\title{
Liquid-Solid Mass Transfer Distributions in Trickle Bed Reactors
}

\author{
Willie Nicol* and Rita Joubert
}

University of Pretoria, Department of Chemical Engineering, University of Pretoria, Lynnwood Road, Hatfield, Pretoria 0002, South Africa

*Corresponding author. E-mail: willie.nicol@up.ac.za

\begin{abstract}
Micro-electrodes with exposed areas ranging from 5-30 $\mathrm{mm}^{2}$ were placed onto $4.5 \mathrm{~mm}$ alumina spheres and used for the sub-particle scale quantification of liquid-solid mass transfer. A novel electrochemical technique was applied where the external cathode wetting fraction and liquid-solid mass transfer were simultaneously quantified. Clear bifurcation of the area-specific liquid-solid mass transfer was observed, providing direct evidence of the two-wetted-zone theory previously inferred from tracer response analysis. The lower hysteresis branch (Levec prewetting) exhibited larger fractions of static wetted area compared to the upper branch (Kan prewetting). The static zones were not completely stagnant and the average static mass transfer rate increased with liquid superficial velocity. The spatial position of the static zones varied for a given packing configuration, while no relationship was found between the positioning of static and residual holdup. Static liquidsolid mass transfer coefficients were found to be higher than those obtained from tracer response analyses on porous particles.
\end{abstract}

Keywords: Trickle bed reactors; hydrodynamics; liquid-solid mass transfer; liquid stagnancy.

\section{Introduction}

Trickle bed reactors (TBRs) remain one of the workhorses of the refining industry. Proper understanding of the complex hydrodynamics of this multiphase reactor is not required for its industrial implementation, and accordingly TBR usage has always outweighed TBR understanding. TBRs in general are associated with large processing quantities, which make these reactors ideal candidates for optimization, intensification and improved design. This has stimulated the quest for improved understanding, and during the past five decades numerous studies have contributed towards this goal. This said, no unifying theory or prediction toolset have resulted from the decades of research due to the complexity of the hydrodynamics and the variability of the reaction conditions employed. Today the quest continues and numerous valuable contributions are made each year.

In TBR research the term 'hydrodynamics' is often used as the subset of measurable parameters describing the flow structures and their influence on the conversion rate. Most notable are the parameters that have a direct influence on the global reaction rate. These will include the different transport parameters and the wetting characteristics of the bed. For processes with a liquid reagent limitation, typically in clean-up processes where small unwanted amounts are removed, the liquid transport to the active site has the potential to inhibit the overall reaction rate. In this regard proper quantification of the liquid-solid mass transfer step is required as well as knowledge of the internal diffusion characteristics within the (sometimes) partially wetted catalyst particles. These two 
transfer steps have become fields within themselves and in this paper we will only focus on the external transport step.

Liquid-solid mass transfer (LSMT) has featured as an important hydrodynamic variable in TBR research since the first studies. Numerous quantification studies and correlations have been published, and the review of Dudukovic et al. [1] can be used as a good reference for these. Notable in these studies is the major variation, sometimes orders of magnitude, in the prediction of the mass transfer coefficient. Compared to single-phase flow predictions of mass transfer [2], TBR correlations cannot be combined into a reliable overall expression. This is attributed to the complexity of the dual phase flow and its influence on the liquid renewal characteristics. In addition, the flow history of the bed is also known to influence the hydrodynamics [3-4], and it has been shown by Joubert et al. [5] that LSMT has similar 'multiplicity' characteristics as other hydrodynamic parameters.

LSMT measurements in TBRs are typically based on bed volume. Quantification of the area-specific LSMT coefficient relies on the knowledge of the external wetting fraction, which is known to be less than unity for lower velocities within the low interaction (or trickle flow) regime. Researchers who report the specific coefficient rely on wetting correlations or measurements made in separate experiments [6] or infer both parameters from reaction experiments [7-8], increasing the uncertainty of the true coefficient value. To further complicate matters it is believed that there is a major variation of mass transfer on the wetted surface. The idea originated from the early residence time distribution (RTD) studies on TBRs, where a mere piston-dispersion model was found to be insufficient to describe the tailing behaviour of the tracer response [9-11]. The RTD tail was attributed to major variation in the velocity distribution within the bed. To incorporate the velocity distribution a simplified two-wetted-zone (TWZ) model was adapted where the liquid was divided into a dynamic and static fraction. The discrete distinction between a zero-velocity static zone and a single-velocity dynamic zone eased the mathematical interpretation of the tracer response, although it was agreed that the true velocity distribution is most likely not well represented by the extreme bimodal distribution of the TWZ model.

Velocity variations entail variation of the mass transfer coefficient, and the TWZ model distinguishes between two liquid-solid mass transfer coefficients. The first describes the LSMT between the dynamic liquid and the particle surface ( $k_{D}$ in this study), and the second describes the LSMT between the static liquid and the particle surface $\left(\mathrm{k}_{\mathrm{s}}\right)$. The model also makes provision for interchange between the static and dynamic liquid sections with a mass transfer coefficient $k_{D S}$ in conjunction with the 'interfacial' area $\left(\mathrm{a}_{\mathrm{DS}}\right)$. The initial RTD studies were all performed on solid packing [7-8], where the only active mass transfer process is the exchange between the dynamic and static liquid sections. This exchange process stands at the core of the piston-dispersion-exchange (PDE) model for interpreting tracer responses. For a critical review of $k_{D S} a_{D S}$ evaluations, the reader should refer to the paper by Mocciaro [12]. Evaluation of $k_{S}$ and $k_{D}$ is much harder, and only two studies have attempted this [13-14]. In both studies porous packing was used in an RTD analysis, whereby the temporary diffusion of the tracer into (and out of) the porous particle is considered in the model employed for the response analysis. Although the idea is sound, the number of unknown and estimated parameters complicates this indirect measurement of $k_{D}$ and $k_{s}$. This said, reasonable agreement was found between the two studies, while the geometric model of Mocciaro [12] gave similar results at high particle Reynolds numbers ( $\operatorname{Re}>50)$. 
In this study we attempt to directly measure the distribution of specific LSMT on a sub-particle scale. Although sub-particle electrodes have been used in other hydrodynamic studies [15], the particle scale was much larger than the scale in this study $\left(d_{p}=4.5 \mathrm{~mm}\right)$. The authors are unaware of any subparticle scale LSMT measurements in TBRs. A previously published electrochemical technique [16] is employed where external wetting and LSMT are simultaneously quantified. Modified $4.5 \mathrm{~mm}$ particles that include three separate electrodes on each particle are used.

\section{Experimental}

The column used in this paper is described in detail in a previous publication by the same authors [16]. A multiple needle-point distributor with 59 points was used in the $44 \mathrm{~mm}$ diameter column with a length of $1 \mathrm{~m}$. Glass beads $(4 \mathrm{~mm})$ were used as inert packing. Five alumina particles $(4.5 \mathrm{~mm})$ each containing three micro-electrodes were placed over the cross-section of the column $350 \mathrm{~mm}$ below the top of the inert packing.

The micro-electrodes were constructed by laser drilling three perpendicular holes of $0.2 \mathrm{~mm}$ through a $4 \mathrm{~mm}$ alumina particle. Small copper end caps were soldered onto isolated copper wire, the wire was threaded through the holes and the cap was glued onto the open side of the holes (the diameter at the entry point of the hole was larger than $0.2 \mathrm{~mm}$ - the laser-drilled hole resulted in a cone-like shape rather than a cylindrical one). The protruding caps were smoothed with the particle surface, after which the exposed copper was electroplated with a nickel-containing solution (24\% $\mathrm{NiSO}_{4}, 4.5 \% \mathrm{NiCl}_{2}$ and $3 \%$ boric acid) at $50{ }^{\circ} \mathrm{C}$. Only the exposed surface was plated due to the internal glue coverage. This was confirmed with the geometry-based calibrations. Figure 1 shows a photograph and diagram of a micro-electrode particle.

The method of simultaneous wetting and mass transfer measurement is explained in [16]. In this prior study a cluster of nickel beads was used as an electrode, while the electrode area in the present study was several orders of magnitude lower. Accordingly re-calibration was required. Quantification of the area-current relationship was complicated by the fact that reference electrodes with known areas were not available. Copper wires with different diameters and lengths were tested, but poor calibration characteristics were obtained, most probably due to non-uniform wire diameters. Twenty-one micro-electrodes were available and area estimates were obtained for each of these. The estimates were based on photographs of each electrode and an assumed spherical cap geometry. Figure 2 gives the total current measured at a potential of $20 \mathrm{mV}$ against the estimated area of the 21 electrodes. The electrodes were submerged into the electrolyte solution, and the stirrer speed in the electrolyte-containing vessel was shown not to affect the current reading. The total current reading was not expected to intersect the origin of the graph due to the effect of nonFaradaic currents. Non-Faradaic current measurements in the absence of $\mathrm{K}_{3} \mathrm{Fe}(\mathrm{CN})_{6}$ and $\mathrm{K}_{4} \mathrm{Fe}(\mathrm{CN})_{6}$ resulted in unacceptable variation, and accordingly the total current was used for the calibration. The calibration line was generated for all estimated areas in excess of $10 \mathrm{~mm}^{2}$ (absolute average error of $8 \%$ ), due to the uncertainty of the small electrode estimates. The fitted calibration line was extrapolated to the smaller electrodes, and electrodes with an estimated area within $20 \%$ of the calibrated area were used in the investigation. The calibration line was used for calculating electrode areas (submersion experiments) as well as the fractional wetting of the electrodes in the trickle bed setup. A voltage of $1 \mathrm{~V}$ was shown to lie in the centre of the mass transfer plateau and was accordingly used for all mass transfer measurements. Non-Faradaic currents at $1 \mathrm{~V}$ were negligible. 
The specific mass transfer coefficient $\left(k_{L}\right)$ was obtained by using the wetted area of the electrode. A NI PXI-4071 digital multimeter was used for current measurements.

Liquid velocities of $1,2,3,4$ and $5 \mathrm{~mm} / \mathrm{s}$ were employed, all at a nitrogen superficial velocity of $20 \mathrm{~mm} / \mathrm{s}$. Packing porosities were estimated to be $0.4 \pm 0.02$. The boundary cases of the 'hysteresis' envelope were represented by Kan (upper boundary) and Levec (lower boundary) prewetting as described by Loudon [17]. Given five velocities and two preconditioning methods, 10 conditions were investigated. The column was repacked twice with four repeat runs for each of the packing configurations (eight repeat measurements for each condition on each electrode). Only eight of the 15 electrodes (three electrode particles) were used due to failure and calibration uncertainty. Table 2 describes the properties of the eight electrodes.

\section{Results and discussion}

\section{Micro-electrode measurements}

As there were eight repeat runs on eight electrodes, 64 measurements were made per condition. Electrode wetting varied from dry (taken as less than $3 \%$ wetted) to complete wetting. Of the total dataset (640 readings) $17 \%$ of the readings was dry, while $71 \%$ had an electrode wetting in excess of $50 \%$. The electrode wetted area measurement was used to calculate the specific LSMT coefficient (kl) from the mass transfer measurements (moles of $\mathrm{Fe}(\mathrm{CN})_{6}{ }^{3-}$ per electrode per time). Figure 3 and Figure 4 give the distribution of the $k_{\mathrm{L}}$ measurements for the selected conditions. The bimodality observed in these figures was found for all the conditions. No relationship existed between electrode size and the magnitude of $k_{L}$. The mass transfer distribution for electrodes situated in residual holdup (liquid remaining after draining) is also presented in Figure 3 and Figure 4. The residual measurements exhibited no decline in mass transfer rate for a one-hour continuous measurement period. Given the accumulative acquisition times used, this indicates that the fractional conversion of the diffusing anion is negligible.

The results are in close agreement with the TWZ theory, which proposes two sets of liquid-solid mass transfer coefficients. It is evident from the distributions that the static liquid zones are not completely stagnant when comparing the lower $k_{L}$ peak to the $k_{R}$ peak. Increasing the liquid velocity shifts the lower $k_{L}$ peak to higher values, and the same is true for the higher $k_{L}$ peak (dynamic wetting). The negligible anion depletion ensures that no electrolyte gradients exist within the bed at any time. The exchange-type mass transfer $\left(k_{D S} a_{D S}\right)$ is therefore completely absent in this system. Adopting the binary approach of the TWZ model, the mass transfer readings can be separated into $\mathrm{k}_{\mathrm{s}}$ $\left(k_{L}<7.5 e-6 \mathrm{~m} / \mathrm{s}\right)$ and $k_{D}\left(k_{L}>7.5 e-6 m / s\right)$ readings. Average values were obtained and the results of the 10 conditions can be seen in Figure 5 . It is interesting to note from Figure 5 that the dependency of $k_{D}$ on superficial velocity is weak (a $30 \%$ improvement in $k_{D}$ with a five-fold increase in superficial velocity), while the average $k_{s}$ values have an $80 \%$ improvement over the velocity span.

\section{Distribution of the wetted fraction}

After prewetting the bed the five velocities were tested without any interruption (starting from the lowest velocity). The bed was drained after the five-velocity 'run'. Each electrode was therefore exposed to 16 separate runs. It was found that the mass transfer state of the electrode (dry, static or dynamic) rarely altered during a run. Only three of the 128 occurrences resulted in a change during a 
run, all where a dry electrode was engulfed by static wetting at higher velocities. Ignoring these rare occurrences, the dry fraction of electrodes can be assumed to be velocity independent, implying that a dry electrode will remain dry for all five velocities. The Levec runs had a dry fraction of $23 \%$ (area basis), and the Kan counterpart had $11 \%$. Although the results cannot accurately predict the overall wetting efficiency ( $f$ ) due to the limited extent of area used, the measurements are in accordance with the general trend found by van Houwelingen [18].

Using the accumulative wetted area, the static wetted fraction $\left(\mathrm{f}_{\mathrm{s}}\right)$ of the Levec runs was calculated to be $37 \%$, with the Kan value at $26 \%$, resulting in a dynamically wetting fraction $\left(f_{D}\right)$ of $40 \%$ and $63 \%$ respectively. It is interesting to note that the Levec runs had a higher $f_{S}$ despite the lower overall wetting (f), which accentuates the influence of prewetting on the static-dynamic liquid distribution within the bed. The perception that the average interstitial velocity determines the magnitude of $k_{L}$ has been challenged by the authors before [5], where it was shown that the higher average interstitial velocities of the Levec mode (lower liquid holdup compared to the Kan mode) did not result in higher $k_{L}$ values. The static-dynamic liquid distribution argument provides an explanation for the observation.

\section{Geometry and position of the static zones}

The micro-electrode measurements provided clear evidence of semi-stagnant zones within the bed. In trickle bed literature the assumed geometry of static zones has always been linked to the observed geometry of residual holdup. It is generally accepted that the pendular ring structures surrounding particle contact points contain the majority of the residual holdup and that the static zones have a similar geometry with either the same, or a slightly smaller volume [12]. The notion of the pendular rings containing the majority of residual holdup has been challenged by van der Merwe [19], who showed for a bed of glass beads that half of the residual volume is contained in structures other than pendular rings. The static holdup view remains unchallenged. Although no volumetric measurements were performed in this study, the area measurements can be used to investigate the position of the static zones and its spatial specificity. These observations can then be used to infer geometric properties of the static holdup.

The first test is to see whether the residual wetted area originated from static or dynamic wetting conditions. Residual wetting is easily detected by the wetting mode of measurement $(20 \mathrm{mV})$. The wetting state (dry, static, dynamic) of an electrode prior to bed drainage can be used to analyse residually wetted electrodes. Since five velocity conditions were tested without stopping liquid irrigation, a total of 16 stops were recorded on the eight micro-electrodes. Of the 128 readings, 22 were dry during operation and remained dry after draining, 66 were dynamically wetted during operation, of which 33 resulted in residual wetting after draining and 40 were statically wetted, of which only 15 resulted in residual wetting after draining. It is very surprising that $70 \%$ of the residually wetted area originated from dynamic wetting. This result challenges the view that residual and static holdup share similar positions and geometries within the bed.

The second test investigates the repeatability of the static zone positioning. The question asked is whether static mass transfer appears on the same electrode for different start-ups when the same packing configuration is employed. The answer is provided in Figure 6 , which gives the distribution of dry, static and dynamic wetting for each micro-electrode. Figure 6 only reports on one packing configuration, although similar trends were obtained for the other configuration. Upon restarting or 
commencing irrigation, major changes occurred with regard to the wetting type, suggesting new flow paths and static holdup positioning. It is evident from Figure 6 that most electrodes experienced all three wetting types. If pendular rings represented the static holdup geometry, electrodes in the vicinity of a contact point would have resulted in repeatable static wetting. None of the electrodes exhibited this behaviour and no evidence of spatial preference for static wetting was observed.

It is safe to assume that residual holdup appears in spaces where the solid interfacial area per volume is high. Particle contact points are representative of these spaces. From a 3-dimensional perspective these spaces have been represented as pore necks [20] where the pore cross-sectional area is at a minimum. In the 'capillary gate' theory represented in this study, the pore necks are used as possible blockage points, where capillary forces are able to withstand the dynamic pressure above the pore neck. The pores above the blocked pore neck tend to be liquid filled compared to unblocked pores, where both gas and liquid are present in the pore. Tomography visualisations indicated that Levec prewetting resulted in a larger fraction of liquid-filled (or blocked) pores when compared to Kan prewetting. The analogy can be extended to the findings in this study, where it is proposed that the flooded pores are associated with static wetting. As discussed before, the static zones (or flooded pores) are not completely stagnant and dependant on the liquid superficial velocity. This can be attributed to interfacial exchange with dynamic liquid or slow leaking through other exits within the pore. The drainage of a flooded pore in the absense of irrigation is evident from the static area not ending up as residual area. The static area that does end up as residual area corresponds to micro electrodes situated near a blocked pore neck. The repeat runs also suggest that pore blocking will not necessarily occur at the same pore neck. The dynamic wetted area that ends up as residual wetted area corresponds to electrodes situated in unblocked pore necks, which are regions of high solid interfacial area per volume where capillary forces have no effect during irrigation. It is therefore proposed that static zones have pore geometry, while only the pore neck part of the static zone is associated with residual holdup. It is, however, clear from the results that the pore neck blocking points (or closed capillary gates) have no specific spatial preference. This is in agreement with the variability findings of the van der Merwe study [19].

\section{Comparison with literature estimates}

Given the average $k_{s}$ values, Sherwood numbers were calculated using a molecular diffusivity of $5.7 \mathrm{x}$ $10^{-9} \mathrm{~m}^{2} \cdot \mathrm{s}^{-1}$ [21]. Figure 7 compares the results obtained in this study with those of the three studies that did an estimate for $k_{s}$ [12-14]. It is evident that the $k_{s}$ values from the present study are an order of magnitude higher than those from the RTD studies [13, 14]. The predictions from the pendular ring-based geometric model of Mocciaro [12] are higher than those of the RTD studies at the low Reynolds numbers of this study, but they are still much lower than the presented measurements.

\section{Conclusions}

Direct experimental evidence of the TWZ model was presented. The results suggest that the velocity distribution under trickle flow have a bimodal nature, where semi-stagnant or static zones can be detected and distinguished from dynamic zones via liquid-solid mass transfer measurements. The level of stagnancy was shown to be dependent on the liquid superficial velocity, while the static liquid-to-solid mass transfer rates were found to be higher than previously anticipated. 
The positions of the static zones were shown to be spatially non-specific and unrelated to the position of the residual holdup. The effect of the prewetting procedure on the extent of stagnancy was clearly observed. This led to an alternative way of viewing static zones challenging the conventional pendular ring notion. It is proposed that complete pore sections flooded with liquid comprise static holdup where the capillary blockages in the necks of these pores can be related to the prewetting conditions.

\section{References}

[1] M.P. Dudukovic, F. Larachi, P.L. Mills, Multiphase catalytic reactors: a perspective on current knowledge and future trends, Catal. Rev. 44 (2002) 123-246.

[2] P.N. Dwivedi, S.N. Upadhyay, Particle-fluid mass transfer in fixed and fluidized beds, Ind. Eng. Chem. Process Des. Dev. 16(2) (1977) 157-165.

[3] K.M. Kan, P.F. Greenfield, Multiple hydrodynamic states in cocurrent twophase down-flow through packed beds, Ind. Eng. Chem. Process Des. Dev. 17 (1978) 482-485.

[4] J. Levec, K. Grosser, R.G. Carbonell, The hysteretic behaviour of pressure drop and liquid holdup in trickle beds, AIChE J. 34 (1988) 1027-1030.

[5] R. Joubert, W. Nicol, Multiplicity behavior of trickle flow liquid-solid mass transfer, Ind. Eng. Chem. Res. 48 (2009) 8387-8392.

[6] L. Baussaron, C. Julcour-Lebigue, C. Boyer, A.M. Wilhelm, H. Delmas, Effect of partial wetting on liquid/solid mass transfer in trickle bed reactors Chem. Eng. Sci. 62(24) (2007) 7020-7025.

[7] M. Herskowitz, R.G. Carbonell, J.M. Smith, Effectiveness factors and mass transfer in tricklebed reactors, AIChE J. 25(2) (1979) 272-283.

[8] A.J. van Houwelingen, W. Nicol, Parallel hydrogenation for the quantification of wetting efficiency and liquid-solid mass transfer in a trickle-bed reactor, AIChE J. 57(5) (2011) 1310-1319.

[9] G.J. Hoogendoorn, J. Lips, Axial mixing of liquid in gas-liquid flow through packed beds, Can. J. Chem. Eng. 43 (1965) 125-131.

[10] W.P.M. van Swaaij, J.C. Charpentier, J. Villermaux, Residence time distribution in the liquid phase of trickle flow in packed columns, Chem. Eng. Sci. 24 (1969) 1083-1095.

[11] J.M. Hochman, E. Effron, Two-phase cocurrent downflow in packed beds, Ind. Eng. Chem. Fundam. 8 (1969) 63-71.

[12] C. Mocciaro, O.M. Martínez, G.F. Barreto, Assessment of mass transfer in the stagnant liquid regions in trickle-bed reactors, Chem. Eng. J. 173(3) (2011) 813-827.

[13] I. Iliuta, F. Larachi, B.P.A. Grandjean, Residence time, mass transfer and backmixing of the trickle flow reactors containing porous particles, Chem. Eng. Sci. 54 (1999) 4099-4109.

[14] K.D.P. Nigam, I. Iliuta, F. Larachi, Liquid back-mixing and mass transfer effects in trickle-bed reactors filled with porous catalyst particles, Chem. Eng. Process. 41 (2002) 365-371. 
[15] T. Dumas, F. Lesage, V. Sobolik, M.A. Latifi, Local flow direction measurements using trisegmented microelectrode in packed beds Chem. Eng. Res. Des. 87(7) (2009) 962-966.

[16] R. Joubert, W. Nicol, Trickle flow liquid-solid mass transfer and wetting efficiency in small diameter columns, Can. J. Chem. Eng. 91(3) (2013) 441-447.

[17] D.S. Loudon, W. van der Merwe, W. Nicol, Multiple hydrodynamic states in trickle flow: the effect of prewetting procedure on liquid holdup. Pressure drop and gas-liquid mass transfer, Chem. Eng. Sci. 61 (2006) 7551-7562.

[18] A.J. van Houwelingen, C. Sandrock, W. Nicol, Particle wetting distributions in trickle bed reactors, AIChE J. 52 (2006) 3532-3542.

[19] W. van der Merwe, C. Maree, W. Nicol, Nature of residual liquid holdup in packed beds of spherical particles, Ind. Eng. Chem. Res. 43(26) (2004) 8363-8368.

[20] W. van der Merwe, W. Nicol, Trickle flow hydrodynamic multiplicity: experimental observations and pore-scale capillary mechanism, Chem. Eng. Sci. 64 (6)(2009) 1267-1284.

[21] J.C. Bazán, A.J. Arvia, The diffusion of ferro- and ferricyanide ions in aqueous solutions of sodium hydroxide, Electrochim. Acta, 10(10) (1965) 1025-1032. 


\section{Nomenclature}

\begin{tabular}{|l|l|}
\hline$a_{D S}$ & Interfacial area between dynamic and static liquid $\left(\mathrm{m}^{2} / \mathrm{m}^{3}\right)$ \\
\hline$f$ & Overall external wetted fraction of catalyst \\
\hline$f_{D}$ & Dynamically wetted fraction of catalyst \\
\hline$f_{S}$ & Statically wetted fraction of catalyst \\
\hline$k_{D}$ & Dynamic liquid-solid mass transfer coefficient $(\mathrm{m} / \mathrm{s})$ \\
\hline$k_{D S}$ & Dynamic liquid-to-static liquid mass transfer coefficient $(\mathrm{m} / \mathrm{s})$ \\
\hline$k_{L}$ & Combined liquid-solid mass transfer coefficient $(\mathrm{m} / \mathrm{s})$ \\
\hline$k_{R}$ & Liquid-solid mass transfer coefficient in residual holdup $(\mathrm{m} / \mathrm{s})$ \\
\hline$k_{S}$ & Static liquid-solid mass transfer coefficient $(\mathrm{m} / \mathrm{s})$ \\
\hline$R e$ & Particle Reynolds number $(-)$ \\
\hline$S h$ & Static Sherwood number $(-)$ \\
\hline$u_{L}$ & Liquid superficial velocity $(\mathrm{m} / \mathrm{s})$ \\
\hline
\end{tabular}


Figure and Table captions.

Table 1: Properties of the eight micro-electrodes employed in the trickle bed experiments.

Figure 1: Diagram and photo of alumina particle containing three micro-electrodes.

Figure 2: Total current measurements at $20 \mathrm{mV}$ of micro-electrodes plotted against geometrically estimated areas. Only estimated areas in excess of $10 \mathrm{~mm}^{2}$ were used for linear regression. Small electrodes $\left(<10 \mathrm{~mm}^{2}\right)$ with major deviation from the calibration line were discarded.

Figure 3: Histogram of Levec prewetted LSMT coefficients. Bin fractions are reported on right side of $\mathrm{k}_{\mathrm{L}}$ increment. Smoothed connection lines have been added for visual improvement. Distribution of residual holdup was scaled to fit graph.

Figure 4: Histogram of Kan prewetted LSMT coefficients. Bin fractions are reported on right side of $\mathrm{k}_{\mathrm{L}}$ increment. Smoothed connection lines have been added for visual improvement. Distribution of residual holdup was scaled to fit graph.

Figure 5: Average values of $k_{L}$ and $k_{S}$. Bimodal distributions in Figure 3 and 4 were separated at $\mathrm{k}_{\mathrm{L}}=7.5 \mathrm{e}-6 \mathrm{~m} / \mathrm{s}$.

Figure 6: Type of wetting obtained per electrode for a single packing configuration.

Figure 7: Comparison of static mass transfer rates with those of previous investigations. 


\title{
Liquid-Solid Mass Transfer Distributions in Trickle Bed Reactors
}

\author{
Willie Nicol* and Rita Joubert
}

University of Pretoria, Department of Chemical Engineering, University of Pretoria, Lynnwood Road, Hatfield, Pretoria 0002, South Africa

*Corresponding author. E-mail: willie.nicol@up.ac.za

\begin{abstract}
Micro-electrodes with exposed areas ranging from 5-30 $\mathrm{mm}^{2}$ were placed onto $4.5 \mathrm{~mm}$ alumina spheres and used for the sub-particle scale quantification of liquid-solid mass transfer. A novel electrochemical technique was applied where the external cathode wetting fraction and liquid-solid mass transfer were simultaneously quantified. Clear bifurcation of the area-specific liquid-solid mass transfer was observed, providing direct evidence of the two-wetted-zone theory previously inferred from tracer response analysis. The lower hysteresis branch (Levec prewetting) exhibited larger fractions of static wetted area compared to the upper branch (Kan prewetting). The static zones were not completely stagnant and the average static mass transfer rate increased with liquid superficial velocity. The spatial position of the static zones varied for a given packing configuration, while no relationship was found between the positioning of static and residual holdup. Static liquidsolid mass transfer coefficients were found to be higher than those obtained from tracer response analyses on porous particles.
\end{abstract}

Keywords: Trickle bed reactors; hydrodynamics; liquid-solid mass transfer; liquid stagnancy.

\section{Introduction}

Trickle bed reactors (TBRs) remain one of the workhorses of the refining industry. Proper understanding of the complex hydrodynamics of this multiphase reactor is not required for its industrial implementation, and accordingly TBR usage has always outweighed TBR understanding. TBRs in general are associated with large processing quantities, which make these reactors ideal candidates for optimization, intensification and improved design. This has stimulated the quest for improved understanding, and during the past five decades numerous studies have contributed towards this goal. This said, no unifying theory or prediction toolset have resulted from the decades of research due to the complexity of the hydrodynamics and the variability of the reaction conditions employed. Today the quest continues and numerous valuable contributions are made each year.

In TBR research the term 'hydrodynamics' is often used as the subset of measurable parameters describing the flow structures and their influence on the conversion rate. Most notable are the parameters that have a direct influence on the global reaction rate. These will include the different transport parameters and the wetting characteristics of the bed. For processes with a liquid reagent limitation, typically in clean-up processes where small unwanted amounts are removed, the liquid transport to the active site has the potential to inhibit the overall reaction rate. In this regard proper quantification of the liquid-solid mass transfer step is required as well as knowledge of the internal diffusion characteristics within the (sometimes) partially wetted catalyst particles. These two 
transfer steps have become fields within themselves and in this paper we will only focus on the external transport step.

Liquid-solid mass transfer (LSMT) has featured as an important hydrodynamic variable in TBR research since the first studies. Numerous quantification studies and correlations have been published, and the review of Dudukovic et al. [1] can be used as a good reference for these. Notable in these studies is the major variation, sometimes orders of magnitude, in the prediction of the mass transfer coefficient. Compared to single-phase flow predictions of mass transfer [2], TBR correlations cannot be combined into a reliable overall expression. This is attributed to the complexity of the dual phase flow and its influence on the liquid renewal characteristics. In addition, the flow history of the bed is also known to influence the hydrodynamics [3-4], and it has been shown by Joubert et al. [5] that LSMT has similar 'multiplicity' characteristics as other hydrodynamic parameters.

LSMT measurements in TBRs are typically based on bed volume. Quantification of the area-specific LSMT coefficient relies on the knowledge of the external wetting fraction, which is known to be less than unity for lower velocities within the low interaction (or trickle flow) regime. Researchers who report the specific coefficient rely on wetting correlations or measurements made in separate experiments [6] or infer both parameters from reaction experiments [7-8], increasing the uncertainty of the true coefficient value. To further complicate matters it is believed that there is a major variation of mass transfer on the wetted surface. The idea originated from the early residence time distribution (RTD) studies on TBRs, where a mere piston-dispersion model was found to be insufficient to describe the tailing behaviour of the tracer response [9-11]. The RTD tail was attributed to major variation in the velocity distribution within the bed. To incorporate the velocity distribution a simplified two-wetted-zone (TWZ) model was adapted where the liquid was divided into a dynamic and static fraction. The discrete distinction between a zero-velocity static zone and a single-velocity dynamic zone eased the mathematical interpretation of the tracer response, although it was agreed that the true velocity distribution is most likely not well represented by the extreme bimodal distribution of the TWZ model.

Velocity variations entail variation of the mass transfer coefficient, and the TWZ model distinguishes between two liquid-solid mass transfer coefficients. The first describes the LSMT between the dynamic liquid and the particle surface ( $k_{D}$ in this study), and the second describes the LSMT between the static liquid and the particle surface $\left(\mathrm{k}_{\mathrm{s}}\right)$. The model also makes provision for interchange between the static and dynamic liquid sections with a mass transfer coefficient $k_{D S}$ in conjunction with the 'interfacial' area $\left(\mathrm{a}_{\mathrm{DS}}\right)$. The initial RTD studies were all performed on solid packing [7-8], where the only active mass transfer process is the exchange between the dynamic and static liquid sections. This exchange process stands at the core of the piston-dispersion-exchange (PDE) model for interpreting tracer responses. For a critical review of $k_{D S} a_{D S}$ evaluations, the reader should refer to the paper by Mocciaro [12]. Evaluation of $k_{S}$ and $k_{D}$ is much harder, and only two studies have attempted this [13-14]. In both studies porous packing was used in an RTD analysis, whereby the temporary diffusion of the tracer into (and out of) the porous particle is considered in the model employed for the response analysis. Although the idea is sound, the number of unknown and estimated parameters complicates this indirect measurement of $k_{D}$ and $k_{s}$. This said, reasonable agreement was found between the two studies, while the geometric model of Mocciaro [12] gave similar results at high particle Reynolds numbers ( $\operatorname{Re}>50)$. 
In this study we attempt to directly measure the distribution of specific LSMT on a sub-particle scale. Although sub-particle electrodes have been used in other hydrodynamic studies [15], the particle scale was much larger than the scale in this study $\left(d_{p}=4.5 \mathrm{~mm}\right)$. The authors are unaware of any subparticle scale LSMT measurements in TBRs. A previously published electrochemical technique [16] is employed where external wetting and LSMT are simultaneously quantified. Modified $4.5 \mathrm{~mm}$ particles that include three separate electrodes on each particle are used.

\section{Experimental}

The column used in this paper is described in detail in a previous publication by the same authors [16]. A multiple needle-point distributor with 59 points was used in the $44 \mathrm{~mm}$ diameter column with a length of $1 \mathrm{~m}$. Glass beads $(4 \mathrm{~mm})$ were used as inert packing. Five alumina particles $(4.5 \mathrm{~mm})$ each containing three micro-electrodes were placed over the cross-section of the column $350 \mathrm{~mm}$ below the top of the inert packing.

The micro-electrodes were constructed by laser drilling three perpendicular holes of $0.2 \mathrm{~mm}$ through a $4 \mathrm{~mm}$ alumina particle. Small copper end caps were soldered onto isolated copper wire, the wire was threaded through the holes and the cap was glued onto the open side of the holes (the diameter at the entry point of the hole was larger than $0.2 \mathrm{~mm}$ - the laser-drilled hole resulted in a cone-like shape rather than a cylindrical one). The protruding caps were smoothed with the particle surface, after which the exposed copper was electroplated with a nickel-containing solution (24\% $\mathrm{NiSO}_{4}, 4.5 \% \mathrm{NiCl}_{2}$ and $3 \%$ boric acid) at $50{ }^{\circ} \mathrm{C}$. Only the exposed surface was plated due to the internal glue coverage. This was confirmed with the geometry-based calibrations. Figure 1 shows a photograph and diagram of a micro-electrode particle.

The method of simultaneous wetting and mass transfer measurement is explained in [16]. Mass transfer readings were obtained at high voltage (1V), while wetting measurements were performed at low voltage $(20 \mathrm{mV})$ where kinetic limitations of the electrochemical reaction allow for quantification of the wetted area. In the previous study a cluster of nickel beads was used as an electrode, while the electrode area in the present study was several orders of magnitude lower. Accordingly re-calibration was required. Quantification of the area-current relationship was complicated by the fact that reference electrodes with known areas were not available. Copper wires with different diameters and lengths were tested, but poor calibration characteristics were obtained, most probably due to non-uniform wire diameters. Twenty-one micro-electrodes were available and area estimates were obtained for each of these. The estimates were based on photographs of each electrode and an assumed spherical cap geometry. Figure 2 gives the total current measured at a potential of $20 \mathrm{mV}$ against the estimated area of the 21 electrodes. The electrodes were submerged into the electrolyte solution, and the stirrer speed in the electrolytecontaining vessel was shown not to affect the current reading. The total current reading was not expected to intersect the origin of the graph due to the effect of non-Faradaic currents. NonFaradaic current measurements in the absence of $\mathrm{K}_{3} \mathrm{Fe}(\mathrm{CN})_{6}$ and $\mathrm{K}_{4} \mathrm{Fe}(\mathrm{CN})_{6}$ resulted in unacceptable variation, and accordingly the total current was used for the calibration. The calibration line was generated for all estimated areas in excess of $10 \mathrm{~mm}^{2}$ (absolute average error of $8 \%$ ), due to the uncertainty of the small electrode estimates. The fitted calibration line was extrapolated to the smaller electrodes, and electrodes with an estimated area within $20 \%$ of the calibrated area were used in the investigation. The calibration line was used for calculating electrode areas (submersion 
experiments) as well as the fractional wetting of the electrodes in the trickle bed setup. A voltage of $1 \mathrm{~V}$ was shown to lie in the centre of the mass transfer plateau and was accordingly used for all mass transfer measurements. Non-Faradaic currents at $1 \mathrm{~V}$ were negligible. The specific mass transfer coefficient $\left(\mathrm{k}_{\mathrm{L}}\right)$ was obtained by using the wetted area of the electrode. A NI PXI-4071 digital multimeter was used for current measurements.

Liquid velocities of 1, 2, 3, 4 and $5 \mathrm{~mm} / \mathrm{s}$ were employed, all at a nitrogen superficial velocity of $20 \mathrm{~mm} / \mathrm{s}$. Packing porosities were estimated to be $0.4 \pm 0.02$. The boundary cases of the 'hysteresis' envelope were represented by Kan (upper boundary) and Levec (lower boundary) prewetting as described by Loudon [17]. Given five velocities and two preconditioning methods, 10 conditions were investigated. The column was repacked twice with four repeat runs for each of the packing configurations (eight repeat measurements for each condition on each electrode). Only eight of the 15 electrodes (three electrode particles) were used due to failure and calibration uncertainty. Table 2 describes the properties of the eight electrodes.

\section{Results and discussion}

\section{Micro-electrode measurements}

As there were eight repeat runs on eight electrodes, 64 measurements were made per condition. Electrode wetting varied from dry (taken as less than $3 \%$ wetted) to complete wetting. Of the total dataset (640 readings) $17 \%$ of the readings was dry, while $71 \%$ had an electrode wetting in excess of $50 \%$. The electrode wetted area measurement was used to calculate the specific LSMT coefficient (kl) from the mass transfer measurements (moles of $\mathrm{Fe}(\mathrm{CN})_{6}{ }^{3-}$ per electrode per time). Figure 3 and Figure 4 give the distribution of the $k_{L}$ measurements for the selected conditions. The bimodality observed in these figures was found for all the conditions. No relationship existed between electrode size and the magnitude of $\mathrm{k}_{\mathrm{L}}$. The mass transfer distribution for electrodes situated in residual holdup (liquid remaining after draining) is also presented in Figure 3 and Figure 4 . The residual measurements exhibited no decline in mass transfer rate for a one-hour continuous measurement period. Given the accumulative acquisition times used, this indicates that the fractional conversion of the diffusing anion is negligible.

The results are in close agreement with the TWZ theory, which proposes two sets of liquid-solid mass transfer coefficients. It is evident from the distributions that the static liquid zones are not completely stagnant when comparing the lower $k_{L}$ peak to the $k_{R}$ peak. Increasing the liquid velocity shifts the lower $k_{L}$ peak to higher values, and the same is true for the higher $k_{L}$ peak (dynamic wetting). The negligible anion depletion during the experiment ensures that no electrolyte gradients exist within the bed at any time since both the stagnant and dynamic liquid zones contain the same amount of diffusing electrolyte. The exchange-type mass transfer $\left(k_{D S} a_{D S}\right)$ is therefore completely absent in this system as. Adopting the binary approach of the TWZ model, the mass transfer readings can be separated into $k_{S}\left(k_{L}<7.5 e-6 m / s\right)$ and $k_{D}\left(k_{L}>7.5 e-6 m / s\right)$ readings. The results from this single split value were in close agreement to those where the minimum of each distribution was used as split. Average values were obtained and the results of the 10 conditions can be seen in Figure 5. It is interesting to note from Figure 5 that the dependency of $k_{D}$ on superficial velocity is weak (a 30\% improvement in $k_{D}$ with a five-fold increase in superficial velocity), while the average $k_{S}$ values have an $80 \%$ improvement over the velocity span. 


\section{Distribution of the wetted fraction}

After prewetting the bed the five velocities were tested without any interruption (starting from the lowest velocity). The bed was drained after the five-velocity 'run'. Each electrode was therefore exposed to 16 separate runs. It was found that the mass transfer state of the electrode (dry, static or dynamic) rarely altered during a run. Only three of the 128 occurrences resulted in a change during a run, all where a dry electrode was engulfed by static wetting at higher velocities. Ignoring these rare occurrences, the dry fraction of electrodes can be assumed to be velocity independent, implying that a dry electrode will remain dry for all five velocities. The Levec runs had a dry fraction of $23 \%$ (area basis), and the Kan counterpart had $11 \%$. Although the results cannot accurately predict the overall wetting efficiency ( $f$ ) due to the limited extent of area used, the measurements are in accordance with the general trend found by van Houwelingen [18].

Using the accumulative wetted area, the static wetted fraction $\left(f_{s}\right)$ of the Levec runs was calculated to be $37 \%$, with the Kan value at $26 \%$, resulting in a dynamically wetting fraction $\left(f_{D}\right)$ of $40 \%$ and $63 \%$ respectively. It is interesting to note that the Levec runs had a higher $f_{s}$ despite the lower overall wetting (f), which accentuates the influence of prewetting on the static-dynamic liquid distribution within the bed. The perception that the average interstitial velocity determines the magnitude of $k_{L}$ has been challenged by the authors before [5], where it was shown that the higher average interstitial velocities of the Levec mode (lower liquid holdup compared to the Kan mode) did not result in higher $k_{\mathrm{L}}$ values. The static-dynamic liquid distribution argument provides an explanation for the observation.

\section{Geometry and position of the static zones}

The micro-electrode measurements provided clear evidence of semi-stagnant zones within the bed. In trickle bed literature the assumed geometry of static zones has always been linked to the observed geometry of residual holdup. It is generally accepted that the pendular ring structures surrounding particle contact points contain the majority of the residual holdup and that the static zones have a similar geometry with either the same, or a slightly smaller volume [12]. The notion of the pendular rings containing the majority of residual holdup has been challenged by van der Merwe [19], who showed for a bed of glass beads that half of the residual volume is contained in structures other than pendular rings. The static holdup view remains unchallenged. Although no volumetric measurements were performed in this study, the area measurements can be used to investigate the position of the static zones and its spatial specificity. These observations can then be used to infer geometric properties of the static holdup.

The first test is to see whether the residual wetted area originated from static or dynamic wetting conditions. Residual wetting is easily detected by the wetting mode of measurement $(20 \mathrm{mV})$. The wetting state (dry, static, dynamic) of an electrode prior to bed drainage can be used to analyse residually wetted electrodes. Since five velocity conditions were tested without stopping liquid irrigation, a total of 16 stops were recorded on the eight micro-electrodes. Of the 128 readings, 22 were dry during operation and remained dry after draining, 66 were dynamically wetted during operation, of which 33 resulted in residual wetting after draining and 40 were statically wetted, of which only 15 resulted in residual wetting after draining. It is very surprising that $70 \%$ of the residually wetted area originated from dynamic wetting. This result challenges the view that residual and static holdup share similar positions and geometries within the bed. 
The second test investigates the repeatability of the static zone positioning. The question asked is whether static mass transfer appears on the same electrode for different start-ups when the same packing configuration is employed. The answer is provided in Table 2, which gives the distribution of dry, static and dynamic wetting for each micro-electrode. Table 2 only reports on one packing configuration, although similar trends were obtained for the other configuration. Upon restarting or commencing irrigation, major changes occurred with regard to the wetting type, suggesting new flow paths and static holdup positioning. It is evident from Table 2 that most electrodes experienced all three wetting types. If pendular rings represented the static holdup geometry, electrodes in the vicinity of a contact point would have resulted in repeatable static wetting. None of the electrodes exhibited this behaviour and no evidence of spatial preference for static wetting was observed.

It is safe to assume that residual holdup appears in spaces where the solid interfacial area per volume is high. Particle contact points are representative of these spaces. From a 3-dimensional perspective these spaces have been represented as pore necks [20] where the pore cross-sectional area is at a minimum. In the 'capillary gate' theory represented in this study, the pore necks are used as possible blockage points, where capillary forces are able to withstand the dynamic pressure above the pore neck. The pores above the blocked pore neck tend to be liquid filled compared to unblocked pores, where both gas and liquid are present in the pore. Tomography visualisations indicated that Levec prewetting resulted in a larger fraction of liquid-filled (or blocked) pores when compared to Kan prewetting. The analogy can be extended to the findings in this study, where it is proposed that the flooded pores are associated with static wetting. As discussed before, the static zones (or flooded pores) are not completely stagnant and dependant on the liquid superficial velocity. This can be attributed to interfacial exchange with dynamic liquid or slow leaking through other exits within the pore. The drainage of a flooded pore in the absense of irrigation is evident from the static area not ending up as residual area. The static area that does end up as residual area corresponds to micro electrodes situated near a blocked pore neck. The repeat runs also suggest that pore blocking will not necessarily occur at the same pore neck. The dynamic wetted area that ends up as residual wetted area corresponds to electrodes situated in unblocked pore necks, which are regions of high solid interfacial area per volume where capillary forces have no effect during irrigation. It is therefore proposed that static zones have pore geometry, while only the pore neck part of the static zone is associated with residual holdup. It is, however, clear from the results that the pore neck blocking points (or closed capillary gates) have no specific spatial preference. This is in agreement with the variability findings of the van der Merwe study [19].

\section{Comparison with literature estimates}

Given the average $k_{s}$ values, Sherwood numbers were calculated using a molecular diffusivity of $5.7 \mathrm{x}$ $10^{-9} \mathrm{~m}^{2} \cdot \mathrm{s}^{-1}$ [21]. Figure 6 compares the results obtained in this study with those of the three studies that did an estimate for $k_{s}$ [12-14]. It is evident that the $k_{s}$ values from the present study are an order of magnitude higher than those from the RTD studies $[13,14]$. The predictions from the pendular ring-based geometric model of Mocciaro [12] are higher than those of the RTD studies at the low Reynolds numbers of this study, but they are still much lower than the presented measurements.

\section{Conclusions}


Direct experimental evidence of the TWZ model was presented. The results suggest that the velocity distribution under trickle flow has a bimodal nature, where semi-stagnant or static zones can be detected and distinguished from dynamic zones via liquid-solid mass transfer measurements. The level of stagnancy was shown to be dependent on the liquid superficial velocity, while the static liquid-to-solid mass transfer rates were found to be higher than previously anticipated.

The positions of the static zones were shown to be spatially non-specific and unrelated to the position of the residual holdup. The effect of the prewetting procedure on the extent of stagnancy was clearly observed. This led to an alternative way of viewing static zones challenging the conventional pendular ring notion. It is proposed that complete pore sections flooded with liquid comprise static holdup where the capillary blockages in the necks of these pores can be related to the prewetting conditions.

\section{References}

[1] M.P. Dudukovic, F. Larachi, P.L. Mills, Multiphase catalytic reactors: a perspective on current knowledge and future trends, Catal. Rev. 44 (2002) 123-246.

[2] P.N. Dwivedi, S.N. Upadhyay, Particle-fluid mass transfer in fixed and fluidized beds, Ind. Eng. Chem. Process Des. Dev. 16(2) (1977) 157-165.

[3] K.M. Kan, P.F. Greenfield, Multiple hydrodynamic states in cocurrent twophase down-flow through packed beds, Ind. Eng. Chem. Process Des. Dev. 17 (1978) 482-485.

[4] J. Levec, K. Grosser, R.G. Carbonell, The hysteretic behaviour of pressure drop and liquid holdup in trickle beds, AIChE J. 34 (1988) 1027-1030.

[5] R. Joubert, W. Nicol, Multiplicity behavior of trickle flow liquid-solid mass transfer, Ind. Eng. Chem. Res. 48 (2009) 8387-8392.

[6] L. Baussaron, C. Julcour-Lebigue, C. Boyer, A.M. Wilhelm, H. Delmas, Effect of partial wetting on liquid/solid mass transfer in trickle bed reactors Chem. Eng. Sci. 62(24) (2007) 7020-7025.

[7] M. Herskowitz, R.G. Carbonell, J.M. Smith, Effectiveness factors and mass transfer in tricklebed reactors, AIChE J. 25(2) (1979) 272-283.

[8] A.J. van Houwelingen, W. Nicol, Parallel hydrogenation for the quantification of wetting efficiency and liquid-solid mass transfer in a trickle-bed reactor, AIChE J. 57(5) (2011) 1310-1319.

[9] G.J. Hoogendoorn, J. Lips, Axial mixing of liquid in gas-liquid flow through packed beds, Can. J. Chem. Eng. 43 (1965) 125-131.

[10] W.P.M. van Swaaij, J.C. Charpentier, J. Villermaux, Residence time distribution in the liquid phase of trickle flow in packed columns, Chem. Eng. Sci. 24 (1969) 1083-1095.

[11] J.M. Hochman, E. Effron, Two-phase cocurrent downflow in packed beds, Ind. Eng. Chem. Fundam. 8 (1969) 63-71.

[12] C. Mocciaro, O.M. Martínez, G.F. Barreto, Assessment of mass transfer in the stagnant liquid regions in trickle-bed reactors, Chem. Eng. J. 173(3) (2011) 813-827. 
[13] I. Iliuta, F. Larachi, B.P.A. Grandjean, Residence time, mass transfer and backmixing of the trickle flow reactors containing porous particles, Chem. Eng. Sci. 54 (1999) 4099-4109.

[14] K.D.P. Nigam, I. Iliuta, F. Larachi, Liquid back-mixing and mass transfer effects in trickle-bed reactors filled with porous catalyst particles, Chem. Eng. Process. 41 (2002) 365-371.

[15] T. Dumas, F. Lesage, V. Sobolik, M.A. Latifi, Local flow direction measurements using trisegmented microelectrode in packed beds Chem. Eng. Res. Des. 87(7) (2009) 962-966.

[16] R. Joubert, W. Nicol, Trickle flow liquid-solid mass transfer and wetting efficiency in small diameter columns, Can. J. Chem. Eng. 91(3) (2013) 441-447.

[17] D.S. Loudon, W. van der Merwe, W. Nicol, Multiple hydrodynamic states in trickle flow: the effect of prewetting procedure on liquid holdup. Pressure drop and gas-liquid mass transfer, Chem. Eng. Sci. 61 (2006) 7551-7562.

[18] A.J. van Houwelingen, C. Sandrock, W. Nicol, Particle wetting distributions in trickle bed reactors, AIChE J. 52 (2006) 3532-3542.

[19] W. van der Merwe, C. Maree, W. Nicol, Nature of residual liquid holdup in packed beds of spherical particles, Ind. Eng. Chem. Res. 43(26) (2004) 8363-8368.

[20] W. van der Merwe, W. Nicol, Trickle flow hydrodynamic multiplicity: experimental observations and pore-scale capillary mechanism, Chem. Eng. Sci. 64 (6)(2009) 1267-1284.

[21] J.C. Bazán, A.J. Arvia, The diffusion of ferro- and ferricyanide ions in aqueous solutions of sodium hydroxide, Electrochim. Acta, 10(10) (1965) 1025-1032. 


\section{Nomenclature}

\begin{tabular}{|l|l|}
\hline$a_{D S}$ & Interfacial area between dynamic and static liquid $\left(\mathrm{m}^{2} / \mathrm{m}^{3}\right)$ \\
\hline$f$ & Overall external wetted fraction of catalyst \\
\hline$f_{D}$ & Dynamically wetted fraction of catalyst \\
\hline$f_{S}$ & Statically wetted fraction of catalyst \\
\hline$k_{D}$ & Dynamic liquid-solid mass transfer coefficient $(\mathrm{m} / \mathrm{s})$ \\
\hline$k_{D S}$ & Dynamic liquid-to-static liquid mass transfer coefficient $(\mathrm{m} / \mathrm{s})$ \\
\hline$k_{L}$ & Combined liquid-solid mass transfer coefficient $(\mathrm{m} / \mathrm{s})$ \\
\hline$k_{R}$ & Liquid-solid mass transfer coefficient in residual holdup $(\mathrm{m} / \mathrm{s})$ \\
\hline$k_{S}$ & Static liquid-solid mass transfer coefficient $(\mathrm{m} / \mathrm{s})$ \\
\hline$R e$ & Particle Reynolds number $(-)$ \\
\hline$S h$ & Static Sherwood number $(-)$ \\
\hline$u_{L}$ & Liquid superficial velocity $(\mathrm{m} / \mathrm{s})$ \\
\hline
\end{tabular}


Figure and Table captions.

Table 1: Properties of the eight micro-electrodes employed in the trickle bed experiments.

Table 2: Distribution of wetting for a single packing configuration.

Figure 1: Diagram and photo of alumina particle containing three micro-electrodes.

Figure 2: Total current measurements at $20 \mathrm{mV}$ of micro-electrodes plotted against geometrically estimated areas. Only estimated areas in excess of $10 \mathrm{~mm}^{2}$ were used for linear regression. Small electrodes $\left(<10 \mathrm{~mm}^{2}\right)$ with major deviation from the calibration line were discarded.

Figure 3: Histogram of Levec prewetted LSMT coefficients. Bin fractions are reported on right side of $\mathrm{k}_{\mathrm{L}}$ increment. Smoothed connection lines have been added for visual improvement. Distribution of residual holdup was scaled to fit graph.

Figure 4: Histogram of Kan prewetted LSMT coefficients. Bin fractions are reported on right side of $\mathrm{k}_{\mathrm{L}}$ increment. Smoothed connection lines have been added for visual improvement. Distribution of residual holdup was scaled to fit graph.

Figure 5: Average values of $k_{L}$ and $k_{S}$. Bimodal distributions in Figure 3 and 4 were separated at $\mathrm{k}_{\mathrm{L}}=7.5 \mathrm{e}-6 \mathrm{~m} / \mathrm{s}$.

Figure 6: Comparison of static mass transfer rates with those of previous investigations. 


\title{
Liquid-Solid Mass Transfer Distributions in Trickle Bed Reactors
}

\author{
Willie Nicol* and Rita Joubert
}

University of Pretoria, Department of Chemical Engineering, University of Pretoria, Lynnwood Road, Hatfield, Pretoria 0002, South Africa

*Corresponding author. E-mail: willie.nicol@up.ac.za

\begin{abstract}
Micro-electrodes with exposed areas ranging from 5-30 $\mathrm{mm}^{2}$ were placed onto $4.5 \mathrm{~mm}$ alumina spheres and used for the sub-particle scale quantification of liquid-solid mass transfer. A novel electrochemical technique was applied where the external cathode wetting fraction and liquid-solid mass transfer were simultaneously quantified. Clear bifurcation of the area-specific liquid-solid mass transfer was observed, providing direct evidence of the two-wetted-zone theory previously inferred from tracer response analysis. The lower hysteresis branch (Levec prewetting) exhibited larger fractions of static wetted area compared to the upper branch (Kan prewetting). The static zones were not completely stagnant and the average static mass transfer rate increased with liquid superficial velocity. The spatial position of the static zones varied for a given packing configuration, while no relationship was found between the positioning of static and residual holdup. Static liquidsolid mass transfer coefficients were found to be higher than those obtained from tracer response analyses on porous particles.
\end{abstract}

Keywords: Trickle bed reactors; hydrodynamics; liquid-solid mass transfer; liquid stagnancy.

\section{Introduction}

Trickle bed reactors (TBRs) remain one of the workhorses of the refining industry. Proper understanding of the complex hydrodynamics of this multiphase reactor is not required for its industrial implementation, and accordingly TBR usage has always outweighed TBR understanding. TBRs in general are associated with large processing quantities, which make these reactors ideal candidates for optimization, intensification and improved design. This has stimulated the quest for improved understanding, and during the past five decades numerous studies have contributed towards this goal. This said, no unifying theory or prediction toolset have resulted from the decades of research due to the complexity of the hydrodynamics and the variability of the reaction conditions employed. Today the quest continues and numerous valuable contributions are made each year.

In TBR research the term 'hydrodynamics' is often used as the subset of measurable parameters describing the flow structures and their influence on the conversion rate. Most notable are the parameters that have a direct influence on the global reaction rate. These will include the different transport parameters and the wetting characteristics of the bed. For processes with a liquid reagent limitation, typically in clean-up processes where small unwanted amounts are removed, the liquid transport to the active site has the potential to inhibit the overall reaction rate. In this regard proper quantification of the liquid-solid mass transfer step is required as well as knowledge of the internal diffusion characteristics within the (sometimes) partially wetted catalyst particles. These two 
transfer steps have become fields within themselves and in this paper we will only focus on the external transport step.

Liquid-solid mass transfer (LSMT) has featured as an important hydrodynamic variable in TBR research since the first studies. Numerous quantification studies and correlations have been published, and the review of Dudukovic et al. [1] can be used as a good reference for these. Notable in these studies is the major variation, sometimes orders of magnitude, in the prediction of the mass transfer coefficient. Compared to single-phase flow predictions of mass transfer [2], TBR correlations cannot be combined into a reliable overall expression. This is attributed to the complexity of the dual phase flow and its influence on the liquid renewal characteristics. In addition, the flow history of the bed is also known to influence the hydrodynamics [3-4], and it has been shown by Joubert et al. [5] that LSMT has similar 'multiplicity' characteristics as other hydrodynamic parameters.

LSMT measurements in TBRs are typically based on bed volume. Quantification of the area-specific LSMT coefficient relies on the knowledge of the external wetting fraction, which is known to be less than unity for lower velocities within the low interaction (or trickle flow) regime. Researchers who report the specific coefficient rely on wetting correlations or measurements made in separate experiments [6] or infer both parameters from reaction experiments [7-8], increasing the uncertainty of the true coefficient value. To further complicate matters it is believed that there is a major variation of mass transfer on the wetted surface. The idea originated from the early residence time distribution (RTD) studies on TBRs, where a mere piston-dispersion model was found to be insufficient to describe the tailing behaviour of the tracer response [9-11]. The RTD tail was attributed to major variation in the velocity distribution within the bed. To incorporate the velocity distribution a simplified two-wetted-zone (TWZ) model was adapted where the liquid was divided into a dynamic and static fraction. The discrete distinction between a zero-velocity static zone and a single-velocity dynamic zone eased the mathematical interpretation of the tracer response, although it was agreed that the true velocity distribution is most likely not well represented by the extreme bimodal distribution of the TWZ model.

Velocity variations entail variation of the mass transfer coefficient, and the TWZ model distinguishes between two liquid-solid mass transfer coefficients. The first describes the LSMT between the dynamic liquid and the particle surface ( $k_{D}$ in this study), and the second describes the LSMT between the static liquid and the particle surface $\left(\mathrm{k}_{\mathrm{s}}\right)$. The model also makes provision for interchange between the static and dynamic liquid sections with a mass transfer coefficient $k_{D S}$ in conjunction with the 'interfacial' area $\left(\mathrm{a}_{\mathrm{DS}}\right)$. The initial RTD studies were all performed on solid packing [7-8], where the only active mass transfer process is the exchange between the dynamic and static liquid sections. This exchange process stands at the core of the piston-dispersion-exchange (PDE) model for interpreting tracer responses. For a critical review of $k_{D S} a_{D S}$ evaluations, the reader should refer to the paper by Mocciaro [12]. Evaluation of $k_{S}$ and $k_{D}$ is much harder, and only two studies have attempted this [13-14]. In both studies porous packing was used in an RTD analysis, whereby the temporary diffusion of the tracer into (and out of) the porous particle is considered in the model employed for the response analysis. Although the idea is sound, the number of unknown and estimated parameters complicates this indirect measurement of $k_{D}$ and $k_{s}$. This said, reasonable agreement was found between the two studies, while the geometric model of Mocciaro [12] gave similar results at high particle Reynolds numbers ( $\operatorname{Re}>50)$. 
In this study we attempt to directly measure the distribution of specific LSMT on a sub-particle scale. Although sub-particle electrodes have been used in other hydrodynamic studies [15], the particle scale was much larger than the scale in this study $\left(d_{p}=4.5 \mathrm{~mm}\right)$. The authors are unaware of any subparticle scale LSMT measurements in TBRs. A previously published electrochemical technique [16] is employed where external wetting and LSMT are simultaneously quantified. Modified $4.5 \mathrm{~mm}$ particles that include three separate electrodes on each particle are used.

\section{Experimental}

The column used in this paper is described in detail in a previous publication by the same authors [16]. A multiple needle-point distributor with 59 points was used in the $44 \mathrm{~mm}$ diameter column with a length of $1 \mathrm{~m}$. Glass beads $(4 \mathrm{~mm})$ were used as inert packing. Five alumina particles $(4.5 \mathrm{~mm})$ each containing three micro-electrodes were placed over the cross-section of the column $350 \mathrm{~mm}$ below the top of the inert packing.

The micro-electrodes were constructed by laser drilling three perpendicular holes of $0.2 \mathrm{~mm}$ through a $4 \mathrm{~mm}$ alumina particle. Small copper end caps were soldered onto isolated copper wire, the wire was threaded through the holes and the cap was glued onto the open side of the holes (the diameter at the entry point of the hole was larger than $0.2 \mathrm{~mm}$ - the laser-drilled hole resulted in a cone-like shape rather than a cylindrical one). The protruding caps were smoothed with the particle surface, after which the exposed copper was electroplated with a nickel-containing solution (24\% $\mathrm{NiSO}_{4}, 4.5 \% \mathrm{NiCl}_{2}$ and $3 \%$ boric acid) at $50{ }^{\circ} \mathrm{C}$. Only the exposed surface was plated due to the internal glue coverage. This was confirmed with the geometry-based calibrations. Figure 1 shows a photograph and diagram of a micro-electrode particle.

The method of simultaneous wetting and mass transfer measurement is explained in [16]. Mass transfer readings were obtained at high voltage (1V), while wetting measurements were performed at low voltage $(20 \mathrm{mV})$ where kinetic limitations of the electrochemical reaction allow for quantification of the wetted area. In the previous study a cluster of nickel beads was used as an electrode, while the electrode area in the present study was several orders of magnitude lower. Accordingly re-calibration was required. Quantification of the area-current relationship was complicated by the fact that reference electrodes with known areas were not available. Copper wires with different diameters and lengths were tested, but poor calibration characteristics were obtained, most probably due to non-uniform wire diameters. Twenty-one micro-electrodes were available and area estimates were obtained for each of these. The estimates were based on photographs of each electrode and an assumed spherical cap geometry. Figure 2 gives the total current measured at a potential of $20 \mathrm{mV}$ against the estimated area of the 21 electrodes. The electrodes were submerged into the electrolyte solution, and the stirrer speed in the electrolytecontaining vessel was shown not to affect the current reading. The total current reading was not expected to intersect the origin of the graph due to the effect of non-Faradaic currents. NonFaradaic current measurements in the absence of $\mathrm{K}_{3} \mathrm{Fe}(\mathrm{CN})_{6}$ and $\mathrm{K}_{4} \mathrm{Fe}(\mathrm{CN})_{6}$ resulted in unacceptable variation, and accordingly the total current was used for the calibration. The calibration line was generated for all estimated areas in excess of $10 \mathrm{~mm}^{2}$ (absolute average error of $8 \%$ ), due to the uncertainty of the small electrode estimates. The fitted calibration line was extrapolated to the smaller electrodes, and electrodes with an estimated area within $20 \%$ of the calibrated area were used in the investigation. The calibration line was used for calculating electrode areas (submersion 
experiments) as well as the fractional wetting of the electrodes in the trickle bed setup. A voltage of $1 \mathrm{~V}$ was shown to lie in the centre of the mass transfer plateau and was accordingly used for all mass transfer measurements. Non-Faradaic currents at $1 \mathrm{~V}$ were negligible. The specific mass transfer coefficient $\left(\mathrm{k}_{\mathrm{L}}\right)$ was obtained by using the wetted area of the electrode. A NI PXI-4071 digital multimeter was used for current measurements.

Liquid velocities of 1, 2, 3, 4 and $5 \mathrm{~mm} / \mathrm{s}$ were employed, all at a nitrogen superficial velocity of $20 \mathrm{~mm} / \mathrm{s}$. Packing porosities were estimated to be $0.4 \pm 0.02$. The boundary cases of the 'hysteresis' envelope were represented by Kan (upper boundary) and Levec (lower boundary) prewetting as described by Loudon [17]. Given five velocities and two preconditioning methods, 10 conditions were investigated. The column was repacked twice with four repeat runs for each of the packing configurations (eight repeat measurements for each condition on each electrode). Only eight of the 15 electrodes (three electrode particles) were used due to failure and calibration uncertainty. Table 2 describes the properties of the eight electrodes.

\section{Results and discussion}

\section{Micro-electrode measurements}

As there were eight repeat runs on eight electrodes, 64 measurements were made per condition. Electrode wetting varied from dry (taken as less than $3 \%$ wetted) to complete wetting. Of the total dataset (640 readings) $17 \%$ of the readings was dry, while $71 \%$ had an electrode wetting in excess of $50 \%$. The electrode wetted area measurement was used to calculate the specific LSMT coefficient (kl) from the mass transfer measurements (moles of $\mathrm{Fe}(\mathrm{CN})_{6}{ }^{3-}$ per electrode per time). Figure 3 and Figure 4 give the distribution of the $k_{L}$ measurements for the selected conditions. The bimodality observed in these figures was found for all the conditions. No relationship existed between electrode size and the magnitude of $\mathrm{k}_{\mathrm{L}}$. The mass transfer distribution for electrodes situated in residual holdup (liquid remaining after draining) is also presented in Figure 3 and Figure 4 . The residual measurements exhibited no decline in mass transfer rate for a one-hour continuous measurement period. Given the accumulative acquisition times used, this indicates that the fractional conversion of the diffusing anion is negligible.

The results are in close agreement with the TWZ theory, which proposes two sets of liquid-solid mass transfer coefficients. It is evident from the distributions that the static liquid zones are not completely stagnant when comparing the lower $k_{L}$ peak to the $k_{R}$ peak. Increasing the liquid velocity shifts the lower $k_{L}$ peak to higher values, and the same is true for the higher $k_{L}$ peak (dynamic wetting). The negligible anion depletion during the experiment ensures that no electrolyte gradients exist within the bed at any time since both the stagnant and dynamic liquid zones contain the same amount of diffusing electrolyte. The exchange-type mass transfer $\left(k_{D S} a_{D S}\right)$ is therefore completely absent in this system as. Adopting the binary approach of the TWZ model, the mass transfer readings can be separated into $k_{S}\left(k_{L}<7.5 e-6 m / s\right)$ and $k_{D}\left(k_{L}>7.5 e-6 m / s\right)$ readings. The results from this single split value were in close agreement to those where the minimum of each distribution was used as split. Average values were obtained and the results of the 10 conditions can be seen in Figure 5. It is interesting to note from Figure 5 that the dependency of $k_{D}$ on superficial velocity is weak (a 30\% improvement in $k_{D}$ with a five-fold increase in superficial velocity), while the average $k_{S}$ values have an $80 \%$ improvement over the velocity span. 


\section{Distribution of the wetted fraction}

After prewetting the bed the five velocities were tested without any interruption (starting from the lowest velocity). The bed was drained after the five-velocity 'run'. Each electrode was therefore exposed to 16 separate runs. It was found that the mass transfer state of the electrode (dry, static or dynamic) rarely altered during a run. Only three of the 128 occurrences resulted in a change during a run, all where a dry electrode was engulfed by static wetting at higher velocities. Ignoring these rare occurrences, the dry fraction of electrodes can be assumed to be velocity independent, implying that a dry electrode will remain dry for all five velocities. The Levec runs had a dry fraction of $23 \%$ (area basis), and the Kan counterpart had $11 \%$. Although the results cannot accurately predict the overall wetting efficiency ( $f$ ) due to the limited extent of area used, the measurements are in accordance with the general trend found by van Houwelingen [18].

Using the accumulative wetted area, the static wetted fraction $\left(f_{s}\right)$ of the Levec runs was calculated to be $37 \%$, with the Kan value at $26 \%$, resulting in a dynamically wetting fraction $\left(f_{D}\right)$ of $40 \%$ and $63 \%$ respectively. It is interesting to note that the Levec runs had a higher $f_{s}$ despite the lower overall wetting (f), which accentuates the influence of prewetting on the static-dynamic liquid distribution within the bed. The perception that the average interstitial velocity determines the magnitude of $k_{L}$ has been challenged by the authors before [5], where it was shown that the higher average interstitial velocities of the Levec mode (lower liquid holdup compared to the Kan mode) did not result in higher $k_{\mathrm{L}}$ values. The static-dynamic liquid distribution argument provides an explanation for the observation.

\section{Geometry and position of the static zones}

The micro-electrode measurements provided clear evidence of semi-stagnant zones within the bed. In trickle bed literature the assumed geometry of static zones has always been linked to the observed geometry of residual holdup. It is generally accepted that the pendular ring structures surrounding particle contact points contain the majority of the residual holdup and that the static zones have a similar geometry with either the same, or a slightly smaller volume [12]. The notion of the pendular rings containing the majority of residual holdup has been challenged by van der Merwe [19], who showed for a bed of glass beads that half of the residual volume is contained in structures other than pendular rings. The static holdup view remains unchallenged. Although no volumetric measurements were performed in this study, the area measurements can be used to investigate the position of the static zones and its spatial specificity. These observations can then be used to infer geometric properties of the static holdup.

The first test is to see whether the residual wetted area originated from static or dynamic wetting conditions. Residual wetting is easily detected by the wetting mode of measurement $(20 \mathrm{mV})$. The wetting state (dry, static, dynamic) of an electrode prior to bed drainage can be used to analyse residually wetted electrodes. Since five velocity conditions were tested without stopping liquid irrigation, a total of 16 stops were recorded on the eight micro-electrodes. Of the 128 readings, 22 were dry during operation and remained dry after draining, 66 were dynamically wetted during operation, of which 33 resulted in residual wetting after draining and 40 were statically wetted, of which only 15 resulted in residual wetting after draining. It is very surprising that $70 \%$ of the residually wetted area originated from dynamic wetting. This result challenges the view that residual and static holdup share similar positions and geometries within the bed. 
The second test investigates the repeatability of the static zone positioning. The question asked is whether static mass transfer appears on the same electrode for different start-ups when the same packing configuration is employed. The answer is provided in Table 2, which gives the distribution of dry, static and dynamic wetting for each micro-electrode. Table 2 only reports on one packing configuration, although similar trends were obtained for the other configuration. Upon restarting or commencing irrigation, major changes occurred with regard to the wetting type, suggesting new flow paths and static holdup positioning. It is evident from Table 2 that most electrodes experienced all three wetting types. If pendular rings represented the static holdup geometry, electrodes in the vicinity of a contact point would have resulted in repeatable static wetting. None of the electrodes exhibited this behaviour and no evidence of spatial preference for static wetting was observed.

It is safe to assume that residual holdup appears in spaces where the solid interfacial area per volume is high. Particle contact points are representative of these spaces. From a 3-dimensional perspective these spaces have been represented as pore necks [20] where the pore cross-sectional area is at a minimum. In the 'capillary gate' theory represented in this study, the pore necks are used as possible blockage points, where capillary forces are able to withstand the dynamic pressure above the pore neck. The pores above the blocked pore neck tend to be liquid filled compared to unblocked pores, where both gas and liquid are present in the pore. Tomography visualisations indicated that Levec prewetting resulted in a larger fraction of liquid-filled (or blocked) pores when compared to Kan prewetting. The analogy can be extended to the findings in this study, where it is proposed that the flooded pores are associated with static wetting. As discussed before, the static zones (or flooded pores) are not completely stagnant and dependant on the liquid superficial velocity. This can be attributed to interfacial exchange with dynamic liquid or slow leaking through other exits within the pore. The drainage of a flooded pore in the absense of irrigation is evident from the static area not ending up as residual area. The static area that does end up as residual area corresponds to micro electrodes situated near a blocked pore neck. The repeat runs also suggest that pore blocking will not necessarily occur at the same pore neck. The dynamic wetted area that ends up as residual wetted area corresponds to electrodes situated in unblocked pore necks, which are regions of high solid interfacial area per volume where capillary forces have no effect during irrigation. It is therefore proposed that static zones have pore geometry, while only the pore neck part of the static zone is associated with residual holdup. It is, however, clear from the results that the pore neck blocking points (or closed capillary gates) have no specific spatial preference. This is in agreement with the variability findings of the van der Merwe study [19].

\section{Comparison with literature estimates}

Given the average $k_{s}$ values, Sherwood numbers were calculated using a molecular diffusivity of $5.7 \mathrm{x}$ $10^{-9} \mathrm{~m}^{2} \cdot \mathrm{s}^{-1}$ [21]. Figure 6 compares the results obtained in this study with those of the three studies that did an estimate for $k_{s}$ [12-14]. It is evident that the $k_{s}$ values from the present study are an order of magnitude higher than those from the RTD studies $[13,14]$. The predictions from the pendular ring-based geometric model of Mocciaro [12] are higher than those of the RTD studies at the low Reynolds numbers of this study, but they are still much lower than the presented measurements.

\section{Conclusions}


Direct experimental evidence of the TWZ model was presented. The results suggest that the velocity distribution under trickle flow has a bimodal nature, where semi-stagnant or static zones can be detected and distinguished from dynamic zones via liquid-solid mass transfer measurements. The level of stagnancy was shown to be dependent on the liquid superficial velocity, while the static liquid-to-solid mass transfer rates were found to be higher than previously anticipated.

The positions of the static zones were shown to be spatially non-specific and unrelated to the position of the residual holdup. The effect of the prewetting procedure on the extent of stagnancy was clearly observed. This led to an alternative way of viewing static zones challenging the conventional pendular ring notion. It is proposed that complete pore sections flooded with liquid comprise static holdup where the capillary blockages in the necks of these pores can be related to the prewetting conditions.

\section{References}

[1] M.P. Dudukovic, F. Larachi, P.L. Mills, Multiphase catalytic reactors: a perspective on current knowledge and future trends, Catal. Rev. 44 (2002) 123-246.

[2] P.N. Dwivedi, S.N. Upadhyay, Particle-fluid mass transfer in fixed and fluidized beds, Ind. Eng. Chem. Process Des. Dev. 16(2) (1977) 157-165.

[3] K.M. Kan, P.F. Greenfield, Multiple hydrodynamic states in cocurrent twophase down-flow through packed beds, Ind. Eng. Chem. Process Des. Dev. 17 (1978) 482-485.

[4] J. Levec, K. Grosser, R.G. Carbonell, The hysteretic behaviour of pressure drop and liquid holdup in trickle beds, AIChE J. 34 (1988) 1027-1030.

[5] R. Joubert, W. Nicol, Multiplicity behavior of trickle flow liquid-solid mass transfer, Ind. Eng. Chem. Res. 48 (2009) 8387-8392.

[6] L. Baussaron, C. Julcour-Lebigue, C. Boyer, A.M. Wilhelm, H. Delmas, Effect of partial wetting on liquid/solid mass transfer in trickle bed reactors Chem. Eng. Sci. 62(24) (2007) 7020-7025.

[7] M. Herskowitz, R.G. Carbonell, J.M. Smith, Effectiveness factors and mass transfer in tricklebed reactors, AIChE J. 25(2) (1979) 272-283.

[8] A.J. van Houwelingen, W. Nicol, Parallel hydrogenation for the quantification of wetting efficiency and liquid-solid mass transfer in a trickle-bed reactor, AIChE J. 57(5) (2011) 1310-1319.

[9] G.J. Hoogendoorn, J. Lips, Axial mixing of liquid in gas-liquid flow through packed beds, Can. J. Chem. Eng. 43 (1965) 125-131.

[10] W.P.M. van Swaaij, J.C. Charpentier, J. Villermaux, Residence time distribution in the liquid phase of trickle flow in packed columns, Chem. Eng. Sci. 24 (1969) 1083-1095.

[11] J.M. Hochman, E. Effron, Two-phase cocurrent downflow in packed beds, Ind. Eng. Chem. Fundam. 8 (1969) 63-71.

[12] C. Mocciaro, O.M. Martínez, G.F. Barreto, Assessment of mass transfer in the stagnant liquid regions in trickle-bed reactors, Chem. Eng. J. 173(3) (2011) 813-827. 
[13] I. Iliuta, F. Larachi, B.P.A. Grandjean, Residence time, mass transfer and backmixing of the trickle flow reactors containing porous particles, Chem. Eng. Sci. 54 (1999) 4099-4109.

[14] K.D.P. Nigam, I. Iliuta, F. Larachi, Liquid back-mixing and mass transfer effects in trickle-bed reactors filled with porous catalyst particles, Chem. Eng. Process. 41 (2002) 365-371.

[15] T. Dumas, F. Lesage, V. Sobolik, M.A. Latifi, Local flow direction measurements using trisegmented microelectrode in packed beds Chem. Eng. Res. Des. 87(7) (2009) 962-966.

[16] R. Joubert, W. Nicol, Trickle flow liquid-solid mass transfer and wetting efficiency in small diameter columns, Can. J. Chem. Eng. 91(3) (2013) 441-447.

[17] D.S. Loudon, W. van der Merwe, W. Nicol, Multiple hydrodynamic states in trickle flow: the effect of prewetting procedure on liquid holdup. Pressure drop and gas-liquid mass transfer, Chem. Eng. Sci. 61 (2006) 7551-7562.

[18] A.J. van Houwelingen, C. Sandrock, W. Nicol, Particle wetting distributions in trickle bed reactors, AIChE J. 52 (2006) 3532-3542.

[19] W. van der Merwe, C. Maree, W. Nicol, Nature of residual liquid holdup in packed beds of spherical particles, Ind. Eng. Chem. Res. 43(26) (2004) 8363-8368.

[20] W. van der Merwe, W. Nicol, Trickle flow hydrodynamic multiplicity: experimental observations and pore-scale capillary mechanism, Chem. Eng. Sci. 64 (6)(2009) 1267-1284.

[21] J.C. Bazán, A.J. Arvia, The diffusion of ferro- and ferricyanide ions in aqueous solutions of sodium hydroxide, Electrochim. Acta, 10(10) (1965) 1025-1032. 


\section{Nomenclature}

\begin{tabular}{|l|l|}
\hline$a_{D S}$ & Interfacial area between dynamic and static liquid $\left(\mathrm{m}^{2} / \mathrm{m}^{3}\right)$ \\
\hline$f$ & Overall external wetted fraction of catalyst \\
\hline$f_{D}$ & Dynamically wetted fraction of catalyst \\
\hline$f_{S}$ & Statically wetted fraction of catalyst \\
\hline$k_{D}$ & Dynamic liquid-solid mass transfer coefficient $(\mathrm{m} / \mathrm{s})$ \\
\hline$k_{D S}$ & Dynamic liquid-to-static liquid mass transfer coefficient $(\mathrm{m} / \mathrm{s})$ \\
\hline$k_{L}$ & Combined liquid-solid mass transfer coefficient $(\mathrm{m} / \mathrm{s})$ \\
\hline$k_{R}$ & Liquid-solid mass transfer coefficient in residual holdup $(\mathrm{m} / \mathrm{s})$ \\
\hline$k_{S}$ & Static liquid-solid mass transfer coefficient $(\mathrm{m} / \mathrm{s})$ \\
\hline$R e$ & Particle Reynolds number $(-)$ \\
\hline$S h$ & Static Sherwood number $(-)$ \\
\hline$u_{L}$ & Liquid superficial velocity $(\mathrm{m} / \mathrm{s})$ \\
\hline
\end{tabular}


Figure and Table captions.

Table 1: Properties of the eight micro-electrodes employed in the trickle bed experiments.

Table 2: Distribution of wetting for a single packing configuration.

Figure 1: Diagram and photo of alumina particle containing three micro-electrodes.

Figure 2: Total current measurements at $20 \mathrm{mV}$ of micro-electrodes plotted against geometrically estimated areas. Only estimated areas in excess of $10 \mathrm{~mm}^{2}$ were used for linear regression. Small electrodes $\left(<10 \mathrm{~mm}^{2}\right)$ with major deviation from the calibration line were discarded.

Figure 3: Histogram of Levec prewetted LSMT coefficients. Bin fractions are reported on right side of $\mathrm{k}_{\mathrm{L}}$ increment. Smoothed connection lines have been added for visual improvement. Distribution of residual holdup was scaled to fit graph.

Figure 4: Histogram of Kan prewetted LSMT coefficients. Bin fractions are reported on right side of $\mathrm{k}_{\mathrm{L}}$ increment. Smoothed connection lines have been added for visual improvement. Distribution of residual holdup was scaled to fit graph.

Figure 5: Average values of $k_{L}$ and $k_{S}$. Bimodal distributions in Figure 3 and 4 were separated at $\mathrm{k}_{\mathrm{L}}=7.5 \mathrm{e}-6 \mathrm{~m} / \mathrm{s}$.

Figure 6: Comparison of static mass transfer rates with those of previous investigations. 


\begin{tabular}{|c|c|c|}
\hline Electrode & Particle & Area $\left(\mathbf{m m}^{\mathbf{2}}\right)$ \\
\hline 1 & 1 & 16.3 \\
\hline 2 & 2 & 30.1 \\
\hline 3 & 3 & 5.3 \\
\hline 4 & 3 & 27.6 \\
\hline 5 & 3 & 7.3 \\
\hline 6 & 4 & 9.4 \\
\hline 7 & 4 & 19.3 \\
\hline 8 & 5 & 10.4 \\
\hline
\end{tabular}




\begin{tabular}{|c|c|c|c|c|c|c|}
\hline & \multicolumn{3}{|c|}{ Kan Wetting } & \multicolumn{3}{c|}{ Levec Wetting } \\
\hline Electrode & Dry & Static & Dynamic & Dry & Static & Dynamic \\
\hline $\mathbf{1}$ & 0 & 2 & 2 & 2 & 2 & 0 \\
\hline $\mathbf{2}$ & 1 & 0 & 3 & 0 & 3 & 1 \\
\hline $\mathbf{3}$ & 0 & 0 & 4 & 2 & 0 & 2 \\
\hline $\mathbf{4}$ & 0 & 1 & 3 & 0 & 1 & 3 \\
\hline $\mathbf{5}$ & 0 & 1 & 3 & 0 & 3 & 1 \\
\hline $\mathbf{6}$ & 1 & 2 & 1 & 2 & 2 & 0 \\
\hline $\mathbf{7}$ & 0 & 1 & 3 & 0 & 2 & 2 \\
\hline $\mathbf{8}$ & 0 & 0 & 4 & 1 & 2 & 1 \\
\hline
\end{tabular}



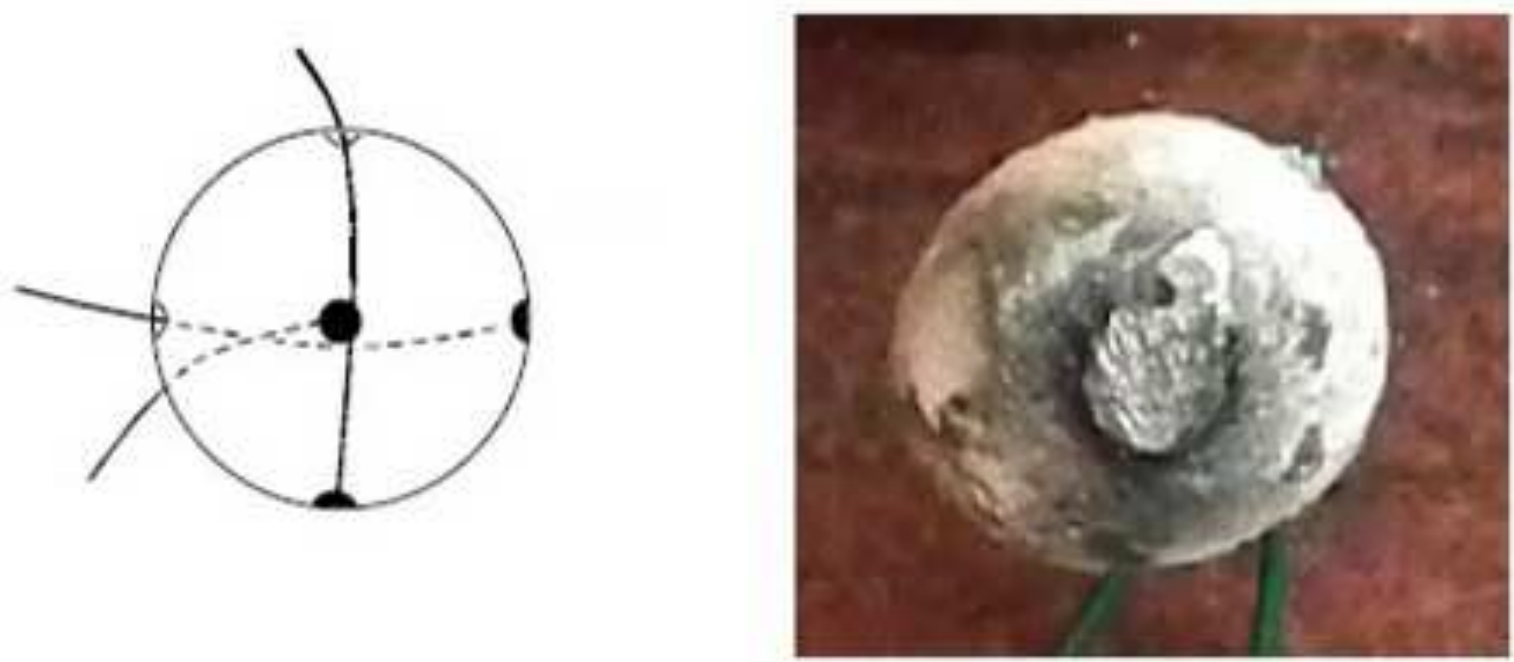


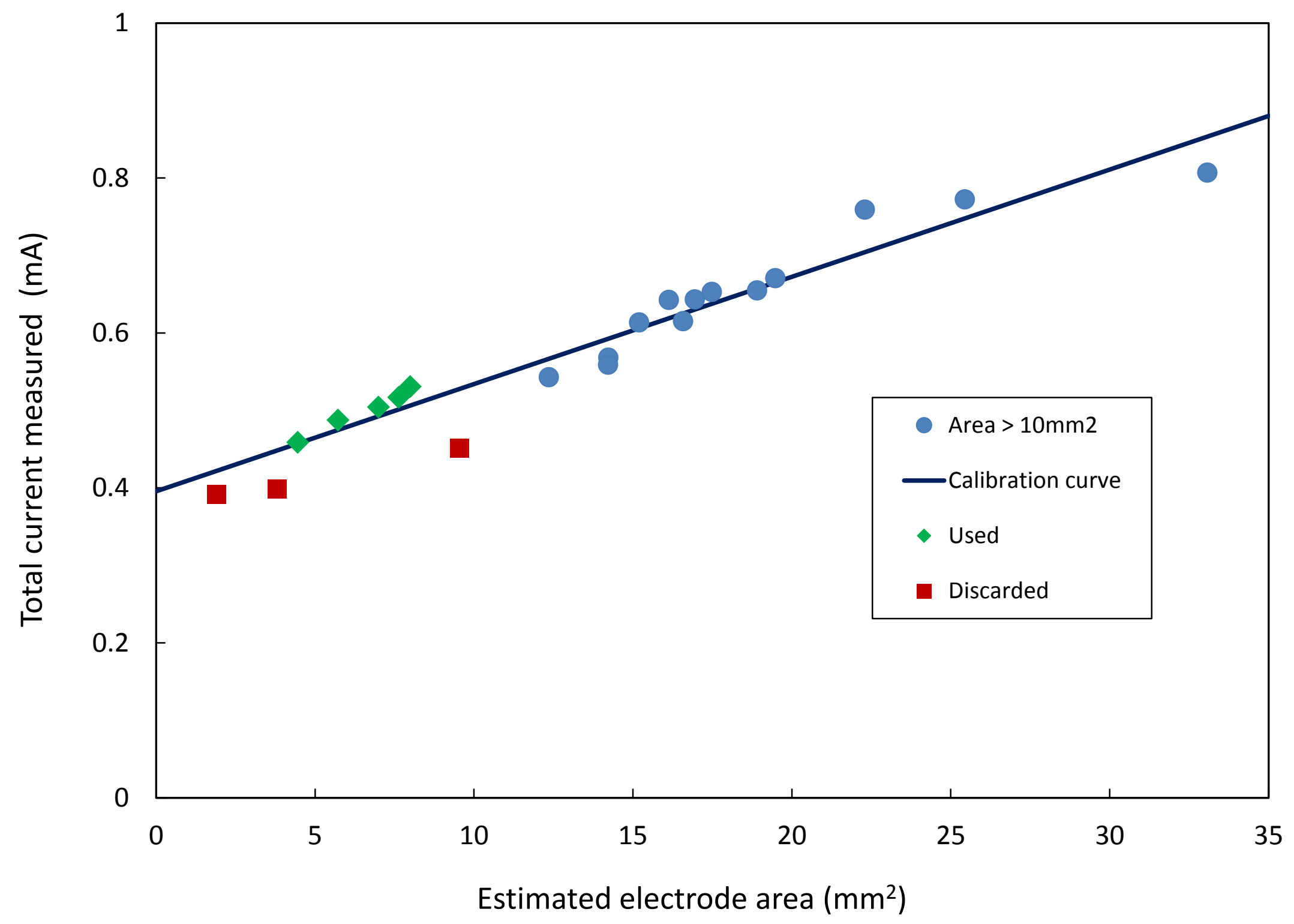




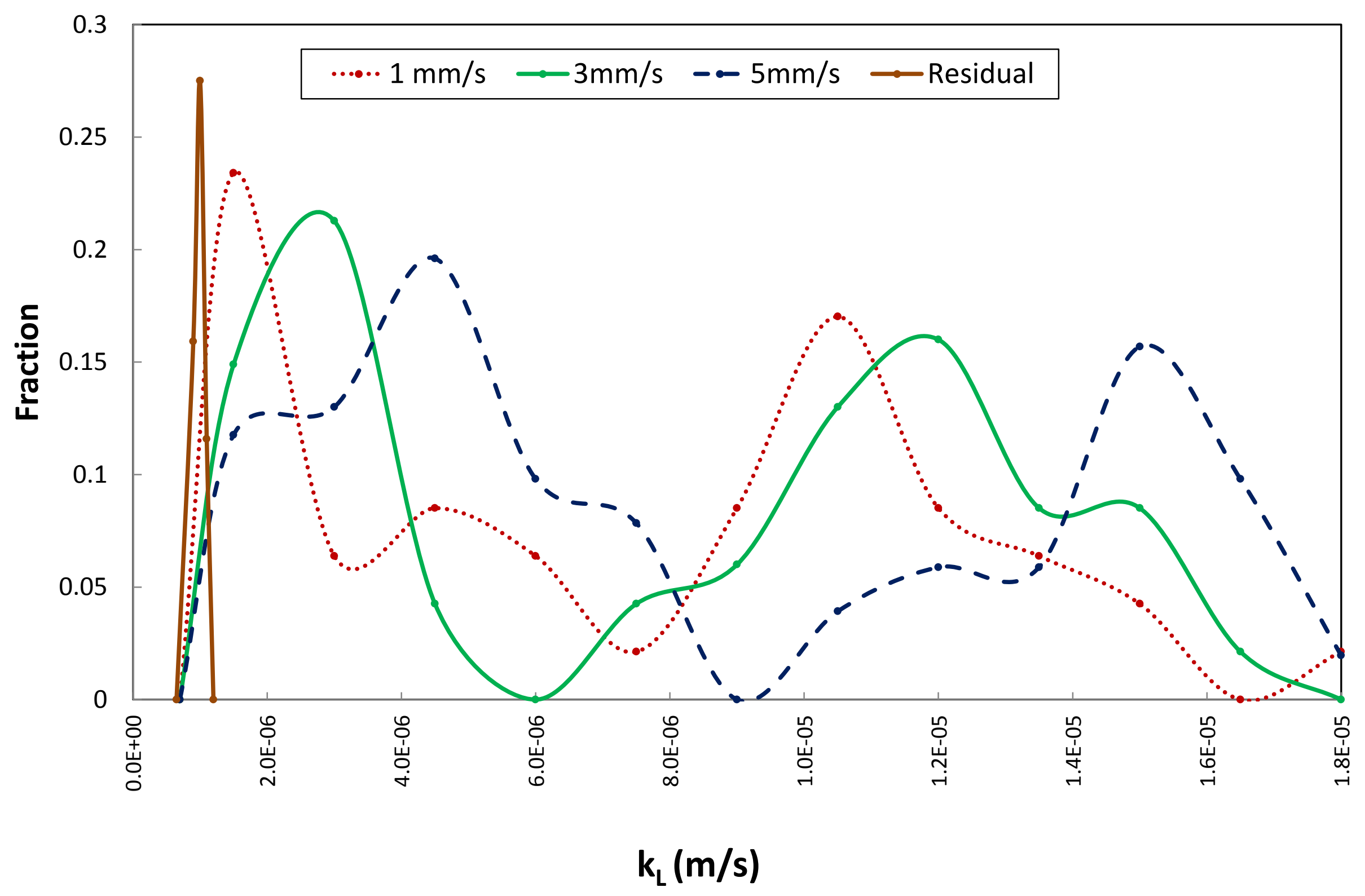




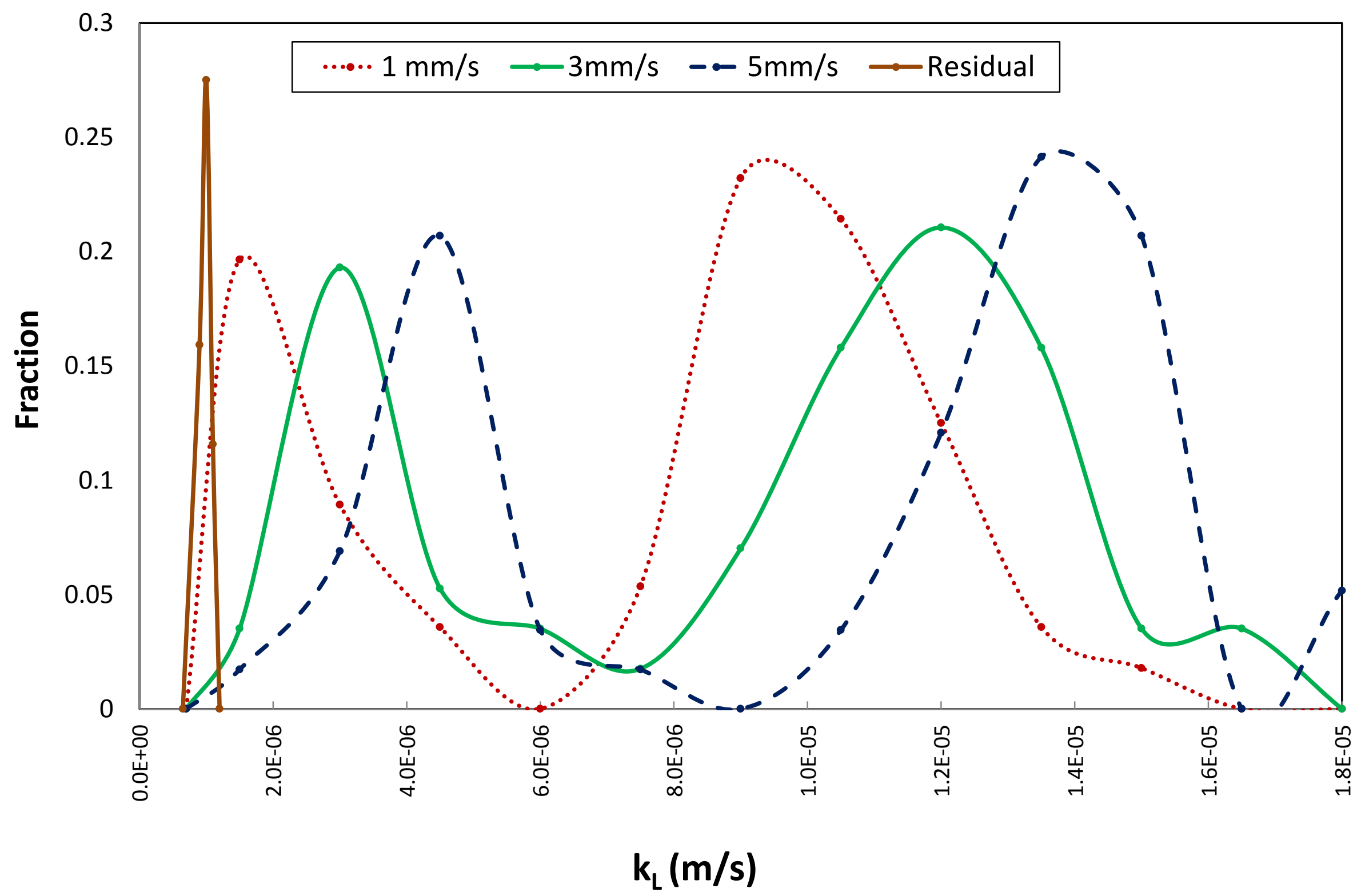




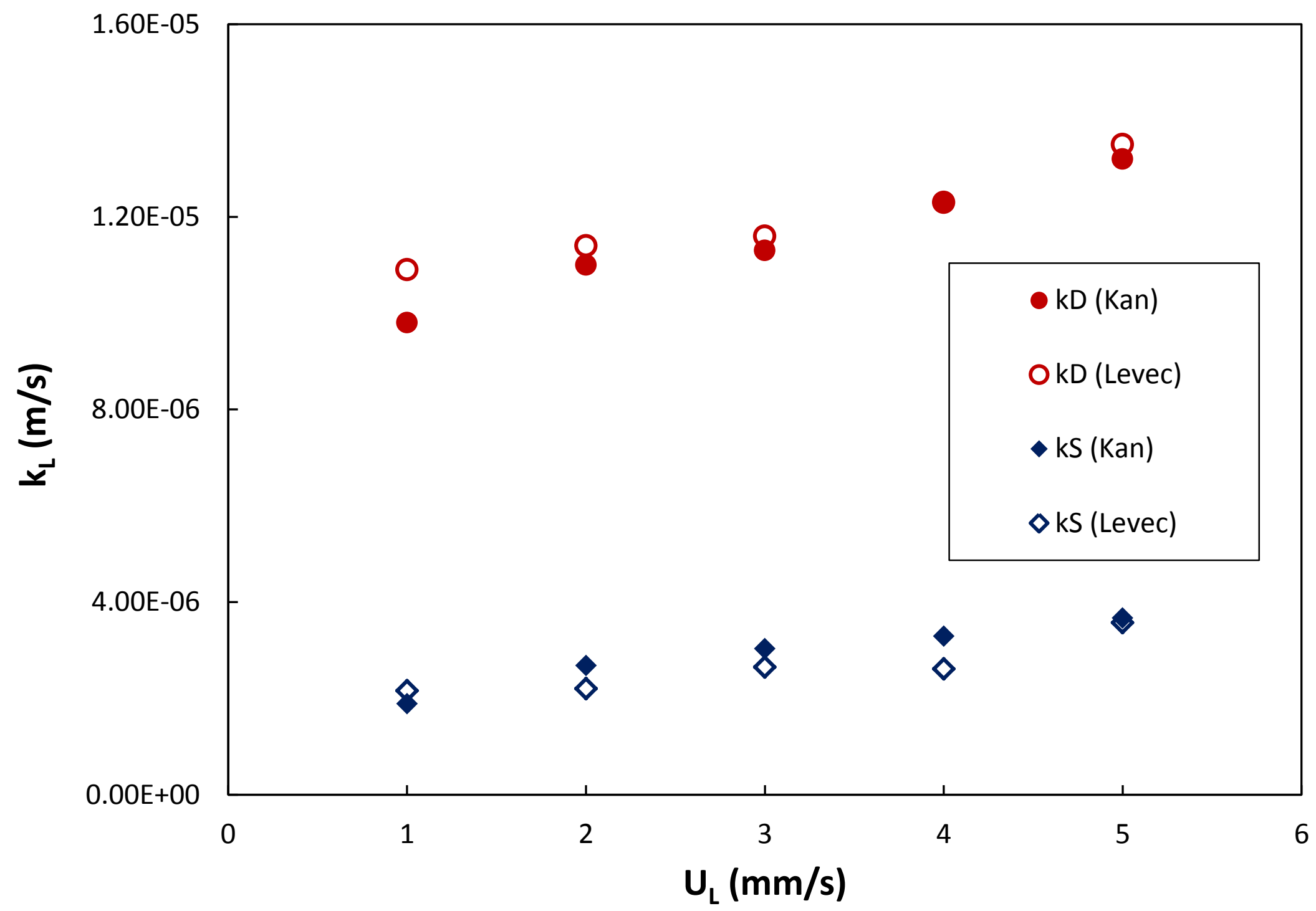




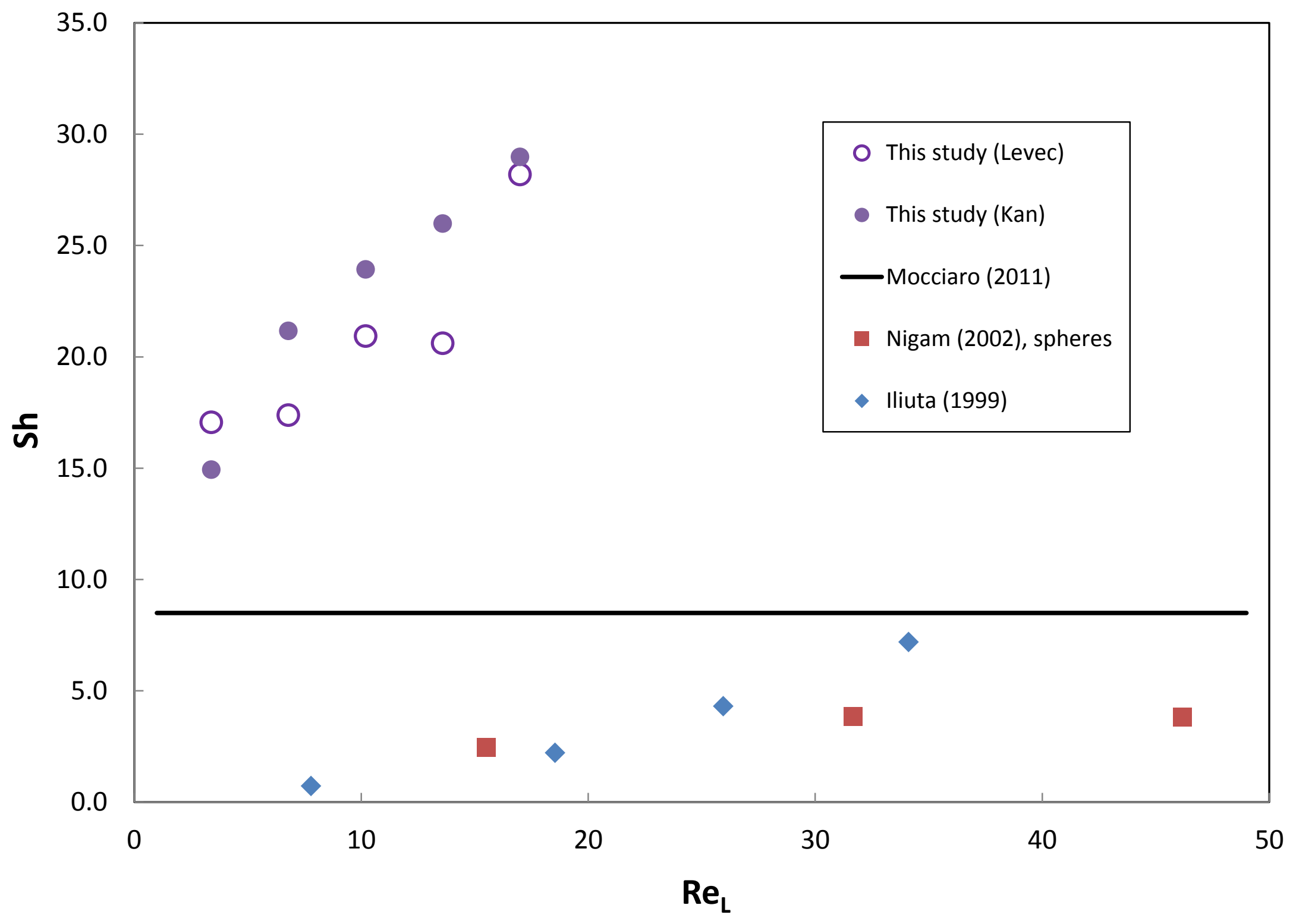

